Cochrane Database of Systematic Reviews

\title{
Systematic screening for the detection of atrial fibrillation (Review)
}

Moran PS, Teljeur C, Ryan M, Smith SM

Moran PS, Teljeur C, Ryan M, Smith SM.

Systematic screening for the detection of atrial fibrillation.

Cochrane Database of Systematic Reviews 2016, Issue 6. Art. No.: CD009586.

DOI: 10.1002/14651858.CD009586.pub3.

www.cochranelibrary.com 
TABLE OF CONTENTS

HEADER 1

ABSTRACT

PLAIN LANGUAGE SUMMARY ....

SUMMARY OF FINDINGS

BACKGROUND

OBJECTIVES

METHODS

RESULTS

Figure 1.

Figure 2.

DISCUSSION

AUTHORS' CONCLUSIONS

ACKNOWLEDGEMENTS

REFERENCES

CHARACTERISTICS OF STUDIES

DATA AND ANALYSES

Analysis 1.1. Comparison 1: Detection of new cases of atrial fibrillation versus routine practice, Outcome 1: Systematic screening vs routine practice

Analysis 1.2. Comparison 1: Detection of new cases of atrial fibrillation versus routine practice, Outcome 2: Opportunistic screening vs routine practice

Analysis 1.3. Comparison 1: Detection of new cases of atrial fibrillation versus routine practice, Outcome 3: Gender subgroups (systematic)

Analysis 1.4. Comparison 1: Detection of new cases of atrial fibrillation versus routine practice, Outcome 4: Age subgroups (systematic)

Analysis 1.5. Comparison 1: Detection of new cases of atrial fibrillation versus routine practice, Outcome 5: Gender subgroups (opportunistic)

Analysis 1.6. Comparison 1: Detection of new cases of atrial fibrillation versus routine practice, Outcome 6: Age subgroups (opportunistic)

Analysis 2.1. Comparison 2: Detection of new cases of atrial fibrillation versus other screening, Outcome 1: Systematic vs opportunistic screening

Analysis 2.2. Comparison 2: Detection of new cases of atrial fibrillation versus other screening, Outcome 2: Gender subgroups .

Analysis 2.3. Comparison 2: Detection of new cases of atrial fibrillation versus other screening, Outcome 3: Age subgroups .... ADDITIONAL TABLES

APPENDICES

WHAT'S NEW

HISTORY

CONTRIBUTIONS OF AUTHORS

DECLARATIONS OF INTEREST

SOURCES OF SUPPORT

DIFFERENCES BETWEEN PROTOCOL AND REVIEW

INDEX TERMS 
[Intervention Review]

\section{Systematic screening for the detection of atrial fibrillation}

Patrick S Moran ${ }^{1}$, Conor Teljeur ${ }^{1}$, Mairin Ryan ${ }^{1}$, Susan M Smith²

1Health Technology Assessment, Health Information and Quality Authority, Dublin, Ireland. ${ }^{2 H R B}$ Centre for Primary Care Research, Department of General Practice, RCSI Medical School, Dublin 2, Ireland

Contact address: Patrick S Moran, patrick.s.moran@gmail.com.

Editorial group: Cochrane Heart Group.

Publication status and date: Stable (no update expected for reasons given in 'What's new'), published in Issue 8, 2021.

Citation: Moran PS, Teljeur C, Ryan M, Smith SM. Systematic screening for the detection of atrial fibrillation. Cochrane Database of Systematic Reviews 2016, Issue 6. Art. No.: CD009586. DOI: 10.1002/14651858.CD009586.pub3.

Copyright @ 2016 The Cochrane Collaboration. Published by John Wiley \& Sons, Ltd.

\section{A B S T R A C T}

\section{Background}

Atrial fibrillation (AF), the most common arrhythmia in clinical practice, is a leading cause of morbidity and mortality. Screening for AF in asymptomatic patients has been proposed as a way of reducing the burden of the disease by detecting people who would benefit from prophylactic anticoagulation therapy before the onset of symptoms. However, for screening to be an effective intervention, it must improve the detection of $\mathrm{AF}$ and provide benefit for those detected earlier as a result of screening.

\section{Objectives}

This review aims to answer the following questions.

Does systematic screening increase the detection of AF compared with routine practice? Which combination of screening population, strategy and test is most effective for detecting AF compared with routine practice? What safety issues and adverse events may be associated with individual screening programmes? How acceptable is the intervention to the target population? What costs are associated with systematic screening for AF?

\section{Search methods}

We searched the Cochrane Central Register of Controlled Trials (CENTRAL), MEDLINE (Ovid) and EMBASE (Ovid) up to 11 November 2015. We searched other relevant research databases, trials registries and websites up to December 2015. We also searched reference lists of identified studies for potentially relevant studies, and we contacted corresponding authors for information about additional published or unpublished studies that may be relevant. We applied no language restrictions.

\section{Selection criteria}

Randomised controlled trials comparing screening for AF with routine practice in people 40 years of age and older were eligible. Two review authors (PM and CT) independently selected trials for inclusion.

\section{Data collection and analysis}

Two review authors (PM and CT) independently assessed risk of bias and extracted data. We used odds ratios (ORs) and $95 \%$ confidence intervals (Cls) to present results for the primary outcome, which is a dichotomous variable. As we identified only one study for inclusion, we performed no meta-analysis. We used the GRADE (Grades of Recommendation, Assessment, Development and Evaluation Working Group) method to assess the quality of the evidence and GRADEPro to create a 'Summary of findings' table.

\section{Main results}

One cluster-randomised controlled trial met the inclusion criteria for this review. This study compared systematic screening (by invitation to have an electrocardiogram (ECG)) and opportunistic screening (pulse palpation during a general practitioner (GP) consultation for any 
reason, followed by an ECG if pulse was irregular) versus routine practice (normal case finding on the basis of clinical presentation) in people 65 years of age or older.

Results show that both systematic screening and opportunistic screening of people over 65 years of age are more effective than routine practice (OR $1.57,95 \% \mathrm{Cl} 1.08$ to 2.26 ; and $\mathrm{OR} 1.58,95 \% \mathrm{Cl} 1.10$ to 2.29 , respectively; both moderate-quality evidence). We found no difference in the effectiveness of systematic screening and opportunistic screening (OR $0.99,95 \% \mathrm{Cl} 0.72$ to 1.37 ; low-quality evidence). A subgroup analysis found that systematic screening and opportunistic screening were more effective in men $(\mathrm{OR} 2.68,95 \% \mathrm{Cl} 1.51$ to 4.76 ; and OR $2.33,95 \% \mathrm{Cl} 1.29$ to 4.19 , respectively) than in women (OR $0.98,95 \% \mathrm{Cl} 0.59$ to 1.62 ; and OR $1.2,95 \% \mathrm{Cl} 0.74$ to 1.93 , respectively). No adverse events associated with screening were reported.

The incremental cost per additional case detected by opportunistic screening was GBP 337, compared with GBP 1514 for systematic screening. All cost estimates were based on data from the single included trial, which was conducted in the UK between 2001 and 2003.

\section{Authors' conclusions}

Evidence suggests that systematic screening and opportunistic screening for AF increase the rate of detection of new cases compared with routine practice. Although these approaches have comparable effects on the overall AF diagnosis rate, the cost of systematic screening is significantly greater than the cost of opportunistic screening from the perspective of the health service provider. Few studies have investigated effects of screening in other health systems and in younger age groups; therefore, caution needs to be exercised in relation to transferability of these results beyond the setting and population in which the included study was conducted.

Additional research is needed to examine the effectiveness of alternative screening strategies and to investigate the effects of the intervention on risk of stroke for screened versus non-screened populations.

\section{PLAIN LANGUAGESUMMARY}

\section{Screening people over 65 years of age for atrial fibrillation increases the rate of detection}

\section{Background}

Atrial fibrillation is a common cardiac arrhythmia that makes the heart beat rapidly and irregularly. This can occur for brief episodes or may be continuous. Symptoms of the disease include heart palpitations, chest pain, shortness of breath, light-headedness and fatigue. The condition is rare in those younger than 40 years of age but is more common as people age. Not everyone with atrial fibrillation experiences symptoms, so some people are unaware that they have it; others may experience mild symptoms that they do not attribute to the disease. Atrial fibrillation hinders efficient flow of blood through the heart, resulting in increased risk of clot formation. If these clots leave the heart, they can block the vessels supplying blood to the brain, causing a stroke. Treatment with anticoagulant medication is designed to prevent the formation of blood clots and can reduce the risk of stroke by over $60 \%$.

\section{Review question}

For a screening programme for atrial fibrillation to be worthwhile, it needs to increase the rate of detection and to benefit those identified to have the problem through screening. The aim of this review was to examine the first part of this question - to find out whether screening increases the number of new diagnoses of atrial fibrillation compared with normal practice, in which people are diagnosed when they consult a health professional with symptoms or risk factors that would lead to testing. This review also examined the safety and rate of uptake of screening, as well as the costs involved.

\section{Results}

The evidence is current to November 2015. This review identified one study that met the inclusion criteria. This study examined systematic screening, whereby everyone over 65 years of age was offered an electrocardiogram (ECG) test, and opportunistic screening, in which those over 65 years of age had their pulse taken when they visited their general practitioner (GP) for any reason and were offered an ECG because an irregular pulse was found. Moderate-quality evidence showed that both of these screening programmes increased the rate of detection of new cases of atrial fibrillation compared with normal practice. Screening appeared to be more effective in men than women, but no information about its effectiveness in different ethnic or socioeconomic groups was provided. As only one study was found, it was not possible to compare the effectiveness of screening in different settings. Uptake of screening was higher for systematic screening than for opportunistic screening, and within both interventions, uptake was higher for men and for the 65 to 74 year age group than for people over 75 years old. No safety issues or complications were reported. From the point of view of the health service provider, systematic screening was more costly than opportunistic screening. However, because all results are based on a single study, one needs to be cautious about applying them outside of the setting (UK primary care) and patient population (over 65 years of age) in which this study was carried out. 


\begin{tabular}{|c|c|c|c|c|c|c|}
\hline \multicolumn{7}{|c|}{\begin{tabular}{|l} 
S U M M A R Y O F F I N D I N G S \\
Summary of findings 1. Screening versus routine practice for detection of atrial fibrillation
\end{tabular}} \\
\hline \multicolumn{7}{|c|}{ Screening versus routine practice for detection of atrial fibrillation } \\
\hline \multicolumn{7}{|c|}{$\begin{array}{l}\text { Patient or population: men and women } 65 \text { years of age or older } \\
\text { Settings: general practice } \\
\text { Intervention: screening } \\
\text { Comparison: routine practice }\end{array}$} \\
\hline \multirow[t]{3}{*}{ Outcomes } & \multicolumn{2}{|c|}{$\begin{array}{l}\text { Illustrative comparative risks* } \\
(95 \% \mathrm{Cl})\end{array}$} & \multirow[t]{3}{*}{$\begin{array}{l}\text { Relative effect } \\
(95 \% \mathrm{CI})\end{array}$} & \multirow{3}{*}{$\begin{array}{l}\text { Number of par- } \\
\text { ticipants } \\
\text { (studies) }\end{array}$} & \multirow{3}{*}{$\begin{array}{l}\text { Quality of the } \\
\text { evidence } \\
\text { (GRADE) }\end{array}$} & \multirow[t]{3}{*}{ Comments } \\
\hline & Assumed risk & Corresponding risk & & & & \\
\hline & Routine prac & Screening & & & & \\
\hline \multirow{4}{*}{$\begin{array}{l}\text { Number of new diagnoses: } \\
\text { systematic screening vs routine } \\
\text { practice } \\
\text { Follow-up: } 12 \text { months }\end{array}$} & \multicolumn{2}{|c|}{ Study population } & \multirow{4}{*}{$\begin{array}{l}\text { OR } 1.57 \\
(1.08 \text { to } 2.26)\end{array}$} & \multirow{4}{*}{$\begin{array}{l}9075 \\
\text { (1 study) }\end{array}$} & \multirow{4}{*}{$\begin{array}{l}\oplus \oplus \oplus \ominus \\
\text { moderate } a\end{array}$} & \multirow{4}{*}{$\begin{array}{l}\text { Downgraded for possible } \\
\text { risk of bias due to an in- } \\
\text { ability to blind study par- } \\
\text { ticipants }\end{array}$} \\
\hline & 10 per 1000 & $\begin{array}{l}16 \text { per } 1000 \\
(11 \text { to } 23)\end{array}$ & & & & \\
\hline & \multicolumn{2}{|c|}{ Moderate population } & & & & \\
\hline & 10 per 1000 & $\begin{array}{l}16 \text { per } 1000 \\
\text { (11 to } 22)\end{array}$ & & & & \\
\hline \multirow{4}{*}{$\begin{array}{l}\text { Number of new diagnoses: op- } \\
\text { portunistic screening vs routine } \\
\text { practice } \\
\text { Follow-up: } 12 \text { months }\end{array}$} & Study popula & & \multirow{4}{*}{$\begin{array}{l}\text { OR } 1.58 \\
\text { (1.10 to } 2.29)\end{array}$} & \multirow{4}{*}{$\begin{array}{l}9088 \\
\text { (1 study) }\end{array}$} & \multirow{4}{*}{$\begin{array}{l}\oplus \oplus \oplus \odot \\
\text { moderate } a\end{array}$} & \multirow{4}{*}{$\begin{array}{l}\text { Downgraded for possible } \\
\text { risk of bias due to an in- } \\
\text { ability to blind study par- } \\
\text { ticipants }\end{array}$} \\
\hline & 10 per 1000 & $\begin{array}{l}16 \text { per } 1000 \\
\text { (11 to } 23)\end{array}$ & & & & \\
\hline & \multicolumn{2}{|c|}{ Moderate population } & & & & \\
\hline & 10 per 1000 & $\begin{array}{l}\mathbf{1 6} \text { per } 1000 \\
(11 \text { to } 22)\end{array}$ & & & & \\
\hline
\end{tabular}

${ }^{\star}$ The basis for assumed risk (e.g. median control group risk across studies) is provided in footnotes. The corresponding risk (and its $95 \%$ confidence interval) is based on the assumed risk in the comparison group and the relative effect of the intervention (and its $95 \% \mathrm{Cl}$ )

Cl: Confidence interval; OR: Odds ratio

GRADE Working Group grades of evidence

High quality: Further research is very unlikely to change our confidence in the estimate of effect 
Moderate quality: Further research is likely to have an important impact on our confidence in the estimate of effect and may change the estimate Low quality: Further research is very likely to have an important impact on our confidence in the estimate of effect and is likely to change the estimate Very low quality: We are very uncertain about the estimate

aPossible risk of bias due to lack of blinding. No deliberate attempt was made to conceal allocation, but failure to do this is not judged to introduce a risk of selective enrolment

\section{Summary of findings 2. Systematic screening versus opportunistic screening for detection of atrial fibrillation}

\section{Systematic screening versus opportunistic screening for detection of atrial fibrillation}

Patient or population: men and women 65 years of age or older

Settings: general practice

Intervention: systematic screening

Comparison: opportunistic screening

\begin{tabular}{|c|c|c|c|c|c|c|}
\hline \multirow[t]{3}{*}{ Outcomes } & \multicolumn{2}{|c|}{ Illustrative comparative risks* $(95 \% \mathrm{CI})$} & \multirow{3}{*}{$\begin{array}{l}\text { Relative effect } \\
(95 \% \mathrm{Cl})\end{array}$} & \multirow{3}{*}{$\begin{array}{l}\text { Number of par- } \\
\text { ticipants } \\
\text { (studies) }\end{array}$} & \multirow{3}{*}{$\begin{array}{l}\text { Quality of the } \\
\text { evidence } \\
\text { (GRADE) }\end{array}$} & \multirow[t]{3}{*}{ Comments } \\
\hline & Assumed risk & Corresponding risk & & & & \\
\hline & $\begin{array}{l}\text { Opportunistic } \\
\text { screening }\end{array}$ & Systematic screening & & & & \\
\hline \multirow{4}{*}{$\begin{array}{l}\text { Number of new } \\
\text { diagnoses } \\
\text { Follow-up: } 12 \\
\text { months }\end{array}$} & Study populati & & \multirow{4}{*}{$\begin{array}{l}\text { OR } 0.99 \\
(0.72 \text { to } 1.37)\end{array}$} & \multirow{4}{*}{$\begin{array}{l}9137 \\
\text { (1 study) }\end{array}$} & \multirow{4}{*}{$\begin{array}{l}\oplus \oplus \ominus \ominus \\
\text { low } a, b\end{array}$} & \multirow{4}{*}{$\begin{array}{l}\text { Downgraded for possible risk of bias } \\
\text { due to an inability to blind study partic- } \\
\text { ipants and for imprecision due to small } \\
\text { events with wide confidence intervals } \\
\text { that cross the line of no effect }\end{array}$} \\
\hline & 16 per 1000 & $\begin{array}{l}\mathbf{1 6} \text { per } 1000 \\
(12 \text { to } 22)\end{array}$ & & & & \\
\hline & \multicolumn{2}{|c|}{ Moderate population } & & & & \\
\hline & 16 per 1000 & $\begin{array}{l}16 \text { per } 1000 \\
(12 \text { to } 22)\end{array}$ & & & & \\
\hline
\end{tabular}

${ }^{*}$ The basis for assumed risk (e.g. median control group risk across studies) is provided in footnotes. The corresponding risk (and its $95 \%$ confidence interval) is based on the assumed risk in the comparison group and the relative effect of the intervention (and its $95 \% \mathrm{Cl}$ )

Cl: Confidence interval; OR: Odds ratio

GRADE Working Group grades of evidence

High quality: Further research is very unlikely to change our confidence in the estimate of effect

Moderate quality: Further research is likely to have an important impact on our confidence in the estimate of effect and may change the estimate

Low quality: Further research is very likely to have an important impact on our confidence in the estimate of effect and is likely to change the estimate

Very low quality: We are very uncertain about the estimate 
Possible risk of bias due to lack of blinding. No deliberate attempt was made to conceal allocation, but failure to do this is not judged to introduce a risk of selective enrolment Imprecision due to small number of events $(<300)$ compared with total participants, with confidence interval crossing the line of no effect 


\section{B A C K G R O U N D}

Screening for atrial fibrillation (AF) in asymptomatic patients has been proposed as a way of reducing the burden of stroke by detecting people who would benefit from prophylactic anticoagulation before the onset of arrhythmia symptoms (Harris 2012). The idea of screening for this condition is not new (e.g. Baxter 1998; Sudlow 1998; Wheeldon 1998), but renewed interest in the topic is associated with the continued high incidence of stroke in many countries, along with data showing significant room for improvement in identification and management of AF (Lip 2012). An overall evaluation of the benefits of a systematic screening programme for AF requires consideration of the probability of adverse health outcomes in the absence of screening, the degree to which screening identifies all people who would suffer these adverse health outcomes and the magnitude of incremental health benefits of earlier versus later treatment resulting from screening (Harris 2011). This review targets the second of these three considerations: Does systematic screening for AF in adults identify people with previously undiagnosed AF more effectively than routine practice?

\section{Description of the condition}

Atrial fibrillation, the most common arrhythmia in clinical practice, is a leading cause of morbidity and mortality (Fuster 2006). The condition is characterised by predominantly unco-ordinated atrial activation with consequent deterioration of atrial mechanical function. Some cases can be asymptomatic; other people with AF may experience palpitations, chest pain, dizziness or, in severe cases, loss of consciousness (NCCCC 2006). The ' 3 P' system classifies AF according to frequency of attacks and whether they are self terminating or require pharmacological or medical cardioversion (Levy 2003). Under this classification system, AF in people who experience two or more episodes that terminate within seven days is classified as paroxysmal AF. If a person has more than one attack that lasts longer than seven days, this is termed persistent AF. Finally, if the AF episode lasts longer than a year or cannot be terminated by cardioversion, it is classified as permanent AF. The frequency of recurrence in paroxysmal AF can increase over time or may degenerate into persistent or eventually permanent AF (NCCCC 2006). Persistent AF that results from an underlying heart condition can often be returned to normal sinus rhythm by treating the underlying cause. In addition to classifying AF in terms of frequency of symptoms, different types of AF may be distinguished by the presence or absence of other underlying heart problems. Lone AF generally applies to individuals younger than 60 years of age without clinical or echocardiographic evidence of cardiopulmonary disease, including hypertension. Valvular and non-valvular AF describes whether associated disorders of the heart valves, including rheumatic mitral valve disease, a prosthetic heart valve or mitral valve repair, are present or absent (Fuster 2006).

In studies that included epidemiological data from the United Stated (USA) and Australia, the prevalence of AF in the general population was estimated to be between $0.4 \%$ and $1 \%$ (Feinberg 1995; Go 2001). Prevalence of AF increases with age (Fuster 2006), rising from $2.3 \%$ in those over 40 years of age to around $8 \%$ in those older than 80 years (Feinberg 1995; Furberg 1994; Wolf 1991). Prevalence estimates vary however, especially in the older age group, with some European epidemiological studies reporting prevalence of approximately $17 \%$ in those $\geq 85$ years of age (Bilato
2009; Heeringa 2006). The median age of patients with AF is 75 years, and $70 \%$ are between 65 and 85 years old (Feinberg 1995). Data from the USA and Canada show that the corresponding incidence of AF for those younger than 40 years of age is less than $0.1 \%$ per year, rising to $1.5 \%$ in women and $2 \%$ in men older than 80 years (Krahn 1995; Psaty 1997; Wolf 1987).

Of particular importance in terms of systematic screening are the prevalence and risk profile of people with AF who have not been diagnosed because they are asymptomatic ('silent AF'), or because their symptoms remain unrecognised. It is estimated that one third of people with AF have no obvious symptoms (Furberg 1994; Savelieva 2000). However, assessing the prevalence of this type of AF is challenging because episodes of arrhythmia may be brief, completely asymptomatic and difficult to detect (Savelieva 2000), and because people experiencing mild symptoms may attribute them to other causes. In the absence of systematic screening, asymptomatic AF is diagnosed incidentally through routine physical examination or pre-operative assessment, or after complications such as stroke or heart failure have occurred. The Framingham study found that among patients who had a stroke as the result of AF, arrhythmia was first diagnosed in $24 \%$ of cases (Wolf 1983). A later report by the same group showed that $18 \%$ of participants who experienced stroke related to AF were newly diagnosed following admission, and another $4.4 \%$ were diagnosed with paroxysmal AF within 14 days (Lin 1995). It has been suggested that silent AF may be associated with silent cerebral infarcts; in one study (Cullinane 1998), silent embolic signals were detected by transcranial Doppler in $13 \%$ of patients with symptomatic AF and in $16 \%$ of those with asymptomatic AF. The relationship between asymptomatic AF or AF with few symptoms and the development of cardiomyopathy was investigated by Grogan et al (Grogan 1992), who found significant improvement in left ventricular function after restoration of sinus rhythm or adequate ventricular rate response during AF. In this study of people who had little or no awareness of their arrhythmia and sought medical attention only when symptoms of heart failure developed, investigators concluded that asymptomatic and undiagnosed AF may cause, rather than result from, severe left ventricular dysfunction. The idea that the risk profile and subsequent clinical management of symptomatic $A F$ may extend to asymptomatic $A F$ is consistent with findings of other studies, which have shown that the type of AF (sustained vs paroxysmal) does not impact risk of stroke or noncentral nervous system (non-CNS) embolism (Hohnloser 2007), and that continuous anticoagulation is warranted in all patients with $\mathrm{AF}$ and risk factors for stroke, even when sinus rhythm appears to be restored and maintained (Wyse 2002).

Atrial fibrillation is associated with increased risk of stroke, congestive heart failure, cognitive dysfunction, reduced quality of life and all-cause mortality (Benjamin 1998; Ott 1997; Stewart 2002). The mortality rate among people with AF is about double that among those with normal sinus rhythm and is linked to the severity of underlying heart disease (Flegel 1987; Kannel 1983; Krahn 1995). Atrial fibrillation contributes to increased risk of stroke due to haemodynamic instability caused by irregular fast heartbeat and thromboembolic complications. For non-valvular AF populations, the two-year age-adjusted incidence of stroke and thromboembolism is increased five-fold (Wolf 1991). This risk increases with age; the Framingham study estimated that the annual risk of stroke attributable to $\mathrm{AF}$ in people 50 to 59 years of age was $1.5 \%$, which rose to $23.5 \%$ among people 80 to 89 years old 
(Wolf 1991). In addition, stroke due to AF is almost twice as likely to be fatal compared with stroke in the absence of AF, and results in greater functional impairment for those who survive (Lin 1996). CHADS2 score (congestive heart failure, hypertension, age $\geq 75$ years, diabetes mellitus, stroke) and, more recently, CHA2DS2-VASC (congestive heart failure, hypertension, age $\geq 75$ years, diabetes mellitus, stroke/transient ischaemic attack, vascular disease, age 65 to 74 years, sex category) provided clinical prediction rules that have been used to estimate risk of stroke in AF and to recommend anticoagulation therapy on the basis of risk factors such as age, sex and clinical history. A CHADS2 score $\geq 1$, corresponding to an annual risk of stroke of $2.8 \%$, indicates that anticoagulation therapy should be considered (ESC 2010).

Over the past 20 years, a $66 \%$ increase in hospitalisations due to $\mathrm{AF}$ has been reported, and AF currently accounts for one third of all hospitalisations for cardiac rhythm disturbances (Freiberg 1997; Fuster 2006; Stewart 2001; Wattigney 2003). This is a result of population ageing, rising prevalence of chronic heart disease and advances in diagnosis. The condition is also associated with high economic costs to the individual and society. It is estimated that the annual cost per patient is approximately EUR 3000 , and the total societal cost in the EU is about EUR 13.5 billion (Fuster 2006).

\section{Description of the intervention}

Systematic screening programmes for AF differ from routine practice by offering tests for AF to a wider range of people than those who present in routine consultations with symptoms, risk factors or other indications for AF testing. A systematic approach would define which test should be used in conjunction with which screening strategy to increase the diagnosis of AF in the community among patients with asymptomatic AF and those who are symptomatic but remain undiagnosed. A screening strategy of opportunistic pulse taking or electrocardiogram (ECG) recording during a routine consultation is treated as a type of systematic screening strategy if all patients who are offered the test are identified a priori and the intervention is offered regardless of the reason for the consultation.

The current gold standard test used to detect AF is a 12-lead ECG interpreted by a cardiologist (Hobbs 2005). Other tests that can be used may involve alternative types of ECGs (limb lead, threelead, five-lead) read by a general practitioner (GP) in combination with preliminary pulse palpation carried out by a physician or nurse. However, pulse palpation is not conclusive on its own (Cooke 2006). As a result of the intermittent nature of paroxysmal AF, frequent repeated electrocardiograms (in which the arrhythmia is present at the time of the test) or continuous ambulatory ECG monitoring is sometimes required (Go 2001). These diagnostic tests can be employed with a range of screening strategies, including opportunistic, targeted and population-based screening. Opportunistic screening usually involves pulse palpation during the course of a routine medical consultation, with recourse to ECG if an irregular pulse is detected. Targeted or structured screening involves identification of certain groups considered to be at higher risk of having AF or groups that can otherwise be singled out for screening. The final option consists of population-based screening programmes, whereby screening is offered to everyone in a particular population who has not previously been diagnosed with AF.
Screening programmes can differ in terms of the population screened, the testing regimen used and the healthcare professionals needed to carry out tests and interpret results. Some interventions described previously have involved one- or two-step processes, depending on whether ECG was used on its own or in conjunction with pulse palpation, with the population tending to be those over 65 years of age. Nurse-led pulse palpation and ECG recorded by physicians or ECG technicians and interpreted by physicians and cardiologists have been reported. For example, Wheeldon et al (Wheeldon 1998) used a one-step strategy, inviting all people over 65 years of age within a primary care practice to have a single 12-lead ECG performed by an ECG technician and interpreted by a hospital cardiologist. In another study, Morgan and Mant (Morgan 2002) randomised patients over 65 years of age to nurse-led pulse palpation or opportunistic pulse palpation prompted by a reminder flag on their medical records, with irregular pulse findings in both arms confirmed by a lead II rhythm strip interpreted by a GP.

Costs associated with systematic screening have been examined in several published studies and are dependent on the screening strategy used and the health system within which they are implemented. Hobbs et al (Hobbs 2005) calculated UK costs for opportunistic screening, systematic screening in high-risk populations and population-based systematic screening (all provided to those over 65 years of age) and found that the incremental cost per additional case detected compared with no screening was lowest for opportunistic screening (GBP 337, GBP 3520 and GBP 1514, respectively). Maeda et al (Maeda 2004) calculated the incremental cost of annual ECG screening for patients between 65 and 85 years of age compared with no screening in Japan at approximately USD 125 for men and USD 150 for women.

\section{How the intervention might work}

Systematic screening for AF in general adult populations could potentially increase rates of diagnosis by identifying people with asymptomatic AF and those who are symptomatic but remain undiagnosed because of failure to attribute symptoms to the arrhythmia and to seek medical attention. A systematic screening programme creates a broader window for diagnosis compared with routine practice because it tests people before the occurrence of symptoms or complications. Therefore, such an intervention may result in greater numbers of people diagnosed or receiving an earlier diagnosis compared with routine practice, as the time period within which AF occurs is likely to be correlated with diagnosis, and AF can begin before the advent of symptoms or complications, or both (Cullinane 1998; Savelieva 2000; Wolf 1983). The effectiveness of the intervention depends on several factors, including prevalence of undiagnosed AF, choice of screening strategy and its acceptability to the patient population and costs associated with the intervention.

Given the relatively high prevalence of AF in older populations and the increased morbidity and mortality associated with it, a screening programme that increases the rate of detection of $\mathrm{AF}$ has the potential to reduce the incidence of adverse cardiovascular events in this high-risk population. Earlier diagnosis of AF will help identify those who would benefit from oral antiplatelet or anticoagulant prophylaxis, calculated to reduce the relative risk of stroke in patients with AF by approximately $20 \%$ and $60 \%$, respectively (ESC 2010; Hart 2007). However, even if systematic 
screening is shown to increase the rate of detection of AF, it will still be necessary to evaluate the magnitude of the overall clinical benefits and harms to avoid bias associated with screening (e.g. over-diagnosis, time-length bias) and to prevent inaccurate conclusions about the effectiveness of treatment in patients identified through systematic screening programmes. Also, the cardiovascular risk profile of screen-detected people may be lower than that of individuals who present with symptoms and comorbidities caused by AF; therefore, the balance of risk (adverse event) and benefit (stroke avoided) associated with prophylactic treatment would likely be altered.

It has been pointed out (Hobbs 2005) that screening for AF meets many of the Wilson-Jungner (Wilson Jungner 1968) criteria for screening for disease. This condition is an important health problem; an accepted treatment is available for people following diagnosis, and a suitable test or examination can be performed. One of the secondary aims of this review is to examine the evidence for some of the other screening criteria, such as acceptability of the test to the population and the cost of case-finding, which should be economically balanced in relation to possible expenditures on medical care as a whole.

\section{Why it is important to do this review}

Atrial fibrillation is under-diagnosed and under-treated, especially among the elderly (ESC 2010; Hobbs 2005; Ogilvie 2010). The condition lends itself to screening because testing is considered to be relatively inexpensive and efficient in terms of the followup required. The primary objective of systematic screening is to reduce the risk of disease within a population through early detection, so that patients can receive treatment to improve their clinical outcomes. This review addresses the first part of that objective, namely, the extent to which screening can be reasonably assumed to increase detection. Given existing evidence in relation to the clinical benefit to be gained from treatment of AF, including asymptomatic $A F$, a systematic screening programme would seem to be an attractive option if it could be shown to increase the rate of detection compared with routine practice. The size of this benefit is unclear because data specifically related to screen-detected patients are not available; however, randomised controlled trial (RCT) data on the primary prevention of ischaemic stroke in AF patients via a vitamin $\mathrm{K}$ antagonist compared with control indicate a relative risk reduction of $67 \%$ (ESC 2010).

This review does not examine the evidence regarding degree of benefit in terms of cardiovascular events avoided or improved quality of life that can result from earlier diagnosis. Nor does it specifically seek to find out whether those identified through systematic screening programmes are more or less likely to eventually suffer the adverse consequences associated with the arrhythmia compared with those diagnosed through routine practice. These issues may be examined in future research, but it is important to know first of all whether use of systematic screening succeeds in its primary objective of increasing the detection rate of $A F$ in the general population. If the introduction of systematic screening programmes fails to increase the detection rate for $A F$, no subsequent change in health benefits can occur and the other criteria need not be examined. On the other hand, if the rate of detection is increased, then subsequent treatment of these patients may reduce their individual risk of experiencing adverse cardiovascular events and may reduce the overall burden of the disease within health systems that introduce such a programme.

\section{O B JECTIVES}

This review aims to answer the following questions.

\section{Does systematic screening increase the detection of AF compared with routine practice?}

The primary objective of the review was to investigate whether evidence shows differences between systematic screening and routine practice in the detection of new cases of AF. Clinical outcomes associated with receiving an earlier diagnosis and subsequent treatment are not within the scope of this review. Earlier detection is assumed to result in improved outcomes within the screened population, as it is generally accepted that effective treatments are available to manage symptoms and reduce the risk of stroke for those with a diagnosis of AF.

\section{Which combination of screening population, strategy and test is most effective for detecting AF compared with routine practice?}

We compared evidence of the effectiveness of different types of screening programmes to find out which method detects AF more effectively. For screening programmes that were shown to be more effective than routine practice, we calculated the magnitude of benefit in terms of overall numbers of new AF cases detected and the number needed to screen to detect one additional case compared with routine practice.

\section{What safety issues and adverse events may be associated with individual screening programmes?}

In any systematic screening programme for AF, a large number of people will be tested to identify a small number who have the arrhythmia. Therefore, any harms associated with screening will affect a much larger proportion of the screened population than the proportion who will experience the benefits associated with receiving a diagnosis. This review assesses the safety and adverse events associated with individual screening programmes. Potential harms depend on the type of screening involved but can include complications associated with testing, anxiety generated by the screening process and inconvenience associated with investigation and follow-up. In this review, we did not assess harms that may occur after diagnosis; these may include adverse events related to treatment, such as haemorrhagic stroke, unnecessary treatments resulting from over-diagnosis or adverse effects of labelling or early diagnosis.

\section{How acceptable is the intervention to the target population?}

One of the most important factors affecting the effectiveness of a screening programme is participation of the target group. If a screening programme is unacceptable to the target population, uptake is likely to be low (Jepson 2000). We evaluated evidence related to the acceptability of individual screening programmes for both healthcare professionals and the screening population involved. Factors that may affect acceptability include anticipated or actual pain, discomfort or embarrassment and follow-up of a positive diagnosis by an intervention or treatment that is considered unacceptable (Jepson 2000). We included in the acceptability analysis costs incurred by the patient over the course of the screening process on the basis that higher costs deter patients from participating in screening programmes (Frazier 1990). 


\section{What costs are associated with systematic screening for} AF?

We assessed direct costs from the perspective of the healthcare provider to obtain data on the practicalities of implementing individual programmes, in terms of likely resource allocation, compared with routine practice. As we will not carry out an overall analysis of the magnitude of health benefits and harms, cost data reported were limited to incremental costs of screening compared with no screening and costs per additional case identified, when such information was available.

\section{MET HOD S}

\section{Criteria for considering studies for this review}

\section{Types of studies}

All randomised controlled trials (RCTs) and cluster-randomised controlled trials (cluster-RCTs) comparing systematic screening versus routine practice were eligible for inclusion, irrespective of language or publication status.

Studies comparing more than one systematic screening programme were eligible for inclusion as long as they included a control arm of routine care.

\section{Types of participants}

Men and women over the age of 40 years. Epidemiological data indicate that $A F$ is extremely uncommon before the age of 40 years, with two-year incidence of $A F$ in the absence of rheumatic heart disease estimated at $0.04 \%$ for men and $0 \%$ for women 30 to 39 years of age (Wolf 1987). Therefore, we excluded younger participants because of the extremely low incidence of $A F$ in this population, which would render systematic screening unfeasible, and to avoid inclusion of studies involving specific patient groups (e.g. paediatric or elite athletes) for which the aetiology, diagnosis and subsequent clinical management of AF may differ from those for age-related onset of AF. Studies that included patients with implantable pacemakers or defibrillators or a previous diagnosis of $A F$ in control and intervention groups were eligible for inclusion as long as these patients were excluded from the final number of newly diagnosed cases of AF reported.

\section{Types of interventions}

Studies eligible for inclusion compared population-based, targeted or opportunistic screening programmes versus no screening, in which the control group relied on routine practice for the diagnosis of $\mathrm{AF}$ over the relevant time period. The method of detecting AF in the intervention group could consist of single-step or multi-step processes, but the diagnosis had to be ultimately confirmed by 12 lead or continuous ambulatory ECG interpreted by a GP, specialist or suitably trained ECG technician or nurse in both intervention and control (or pre-intervention) groups. We excluded interventions that used pulse palpation alone or other types of ECG readings to confirm a diagnosis of AF.

We defined routine practice (control group) as diagnoses made during routine care, incidentally or following presentation with indications for AF testing, that were subsequently confirmed by 12-lead or continuous ambulatory ECG interpreted by a GP, a specialist or a suitably trained ECG technician or nurse. In addition, we required a clear mechanism for recording the number of new diagnoses of AF made over the relevant study period in this group. We differentiated opportunistic screening, by which all members of the intervention group had their pulse recorded during the course of a routine consultation for any reason, from routine practice, whereby AF diagnoses were made following presentation with symptoms of an arrhythmia, or incidentally through other examinations, but when specific AF testing for all patients was not mandated. Studies that used only an alternative systematic screening strategy, instead of routine practice, as the control were not eligible for inclusion.

\section{Types of outcome measures}

\section{Primary outcomes}

The primary outcome under investigation was the difference in the detection of new cases of AF associated with systematic screening compared with routine practice, for individual screening programmes identified as eligible for inclusion in the review and for which a diagnosis of AF was defined as a positive reading on a 12-lead or continuous ambulatory ECG interpreted by a specialist, a physician or a suitably trained ECG technician or nurse. We used this information to calculate the overall difference in the numbers of AF cases detected compared with routine practice, as well as the number needed to screen (NNS) to detect one additional case of AF within the population. If we had identified studies describing multiple systematic screening programmes, then we planned to rank $\mathrm{AF}$ detection rates for each according to their effectiveness when compared with routine practice.

\section{Secondary outcomes}

\section{Acceptability of systematic screening programmes within the target population}

We examined the acceptability of screening in three ways: level of uptake achieved, feedback elicited from participants and healthcare professionals involved and a description of any direct costs associated with screening that were borne by the person to whom the screening programme was offered.

We defined the level of uptake of a systematic screening programme as the percentage of the screening population that participated in the full screening programme. For screening strategies involving more than one stage (e.g. pulse palpation followed by ECG), we defined uptake as those who completed both stages. We also reported data related to the level of uptake among subgroups of the overall population for individual screening programmes.

Issues with regards to acceptability of the intervention to the patient or healthcare professional, or both, may depend on the type of screening programme involved. Screening programmes were eligible for inclusion if they were based on primary data collected through the use of questionnaires, interviews or other means of eliciting the experiences and opinions of patients or healthcare professionals involved in care. We provided a narrative summary of issues affecting the acceptability of different types of screening programmes.

We described costs incurred by the patient taking part in the screening programme as part of the analysis of acceptability of the intervention to the patient, with higher costs assumed to be less acceptable than lower or no costs. 
Adverse events associated with systematic screening programmes for AF

We recorded the rate and severity of complications or adverse events associated with ECG and other forms of AF testing.

We included psychological distress, change in quality of life and impact on well-being if these outcomes were measured on a validated scale. We excluded adverse events related to treatment following a diagnosis of AF.

\section{Analysis of costs associated with systematic screening programmes for AF}

We included in the analysis of this outcome only direct costs from the perspective of the healthcare provider. When possible, we provided a description of the operational and training costs associated with screening, along with the incremental costs of screening and costs per additional case detected compared with a policy of no screening.

\section{Changes to the known prevalence of AF}

Using data from patients included in RCT studies, we calculated an estimate of the prevalence of $\mathrm{AF}$ within the screening population.

\section{Search methods for identification of studies}

\section{Electronic searches}

We updated searches of the following databases on 10 November 2015 to find relevant RCTs and provided the search strategies in Appendix 1.

- Cochrane Central Register of Controlled Trials (CENTRAL) (2015, Issue 10 of 12).

- MEDLINE and MEDLINE In-Process (Ovid) 1946 to 10 November 2015.

- EMBASE Classic and EMBASE (Ovid) 1947 to 9 November 2015.

We also searched the Cumulative Index to Nursing and Allied Health Literature (CINAHL) (EBSCO) on 1 June 2012.

We applied the Cochrane sensitivity maximising RCT filter to MEDLINE and EMBASE, and applied terms used by Cochrane to limit a search to RCTs (Lefebvre 2011).

\section{Searching other resources}

We searched the following trial registries for relevant studies up to December 2014.

- ClinicalTrials.gov (www.clinicaltrials.gov).

- International Standard Randomised Controlled Trial Number (ISRCTN) Registry (http://isrctn.org/).

- Stroke Trials Directory (www.strokecenter.org/trials).

- World Health Organization (WHO) International Clinical Trials Registry Platform (http://apps.who.int/trialsearch/).

- EU Clinical Trials Register (www.clinicaltrialsregister.eu).

We also searched the following websites for relevant studies up to 1 June 2012.

- European Stroke Conference (http://eurostroke.eu/).
- European Heart Rhythm Association (EHRA; www.escardio.org/ The-ESC/Communities/European-Heart-Rhythm-Association(EHRA)/EHRA).

- American College of Cardiology (ACC; www.acc.org).

We searched the reference lists of all included papers to identify potentially relevant articles. When required, we contacted lead authors and investigators to ask for information about additional published or unpublished studies that may be relevant.

We applied no date or language restrictions to any of the searches.

\section{Data collection and analysis}

\section{Selection of studies}

A single review author (PM) carried out preliminary screening of all returned results to eliminate studies that clearly were not relevant. Two review authors (PM and CT) independently assessed the eligibility of studies and identified multiple reports from single studies, resolving disagreements by discussion.

\section{Data extraction and management}

Two review authors (PM and CT) independently extracted data, resolving disagreements by discussion.

We extracted the following data from included studies.

- All relevant data pertaining to study characteristics and primary and secondary outcomes of interest.

* This included study setting, number of centres, funding, participant characteristics, screening method and AF test used, number of participants in each arm, AF cases detected, participant uptake, factors affecting participation, quality of life data related to screening, other adverse events or complications, prevalence of AF in the study population and cost data related to screening.

- All data required to perform risk of bias assessment.

* This included study design, allocation method, blinding procedures if any, participant withdrawals, reporting of all outcomes and risk of contamination. We examined studies for other potential threats to the validity of their findings that were specific to the particular trial design and clinical setting.

\section{Assessment of risk of bias in included studies}

Two review authors (PM and CT) independently assessed the risk of bias in included studies in accordance with guidelines stated in the Cochrane Handbook for Systematic Reviews of Interventions (Higgins 2011), using the risk of bias tool of The Cochrane Collaboration included in section 8.5 of the Cochrane Handbook for Systematic Reviews of Interventions, which categorises studies as having high, low or unclear risk of bias.

This review was not subject to some types of bias associated with screening (e.g. lead-time bias) because the primary outcome was differences in the rate of detection as opposed to survival or time-to-event data. Biases associated with screening studies that could result in incorrect conclusions include time-length bias and over-diagnosis bias. Time-length is a form of selection bias whereby patients with slowly progressing AF are more likely to be identified by screening than people for whom onset of symptoms and associated adverse cardiovascular events are more acute. This occurs because the longer time period within which people are 
asymptomatic but would test positive for AF makes them more likely to be picked up by screening. Similar to lead-time bias, this can make it appear that cases discovered through screening fare better than those that present with symptoms, but in reality the difference is not due to screening but occurs because screening disproportionately identifies slowly progressing AF. Despite the fact that no time-to-event data were included, a risk to this review from time-length bias arises from overestimation of the benefit of screening when it is assumed that all identified cases will derive the same benefit from anticoagulation prophylaxis to reduce the risk of stroke, when in fact patients who would benefit the most (i.e. those with more severe, rapidly progressing AF) are least likely to be identified through screening. This is also the case for paroxysmal $\mathrm{AF}$, which is likely to be more difficult to detect through screening than persistent or permanent AF. However, available evidence suggests that stroke risk in these two groups is similar (Friberg 2010). A similar situation exists with regard to over-diagnosis bias, whereby implementation of a screening programme may result in diagnosis and treatment of asymptomatic AF patients when, in the absence of a screening programme, they may never have become symptomatic or suffered a stroke as a result of the arrhythmia. However, these biases do not introduce systematic errors into the primary outcome of concern in this review (AF diagnosis rate), rather they may lead to over-interpretation of clinical gains associated with increasing the detection of $\mathrm{AF}$ through systematic screening.

We assessed studies for other sources of bias that may be relevant to specific methods used in performance of the research. For instance, some screening programmes involve a two-step process to test for AF, with manual pulse palpation performed initially, followed by an ECG when an irregular pulse is found. As the accuracy of pulse palpation is affected by the skill and experience of the medical practitioner (Hobbs 2005), an intervention bias related to variation in the proficiency of different healthcare professionals performing the test may influence study results. However, as this is not a review of diagnostic test accuracy, as long as the intervention specifies the type of reader used, it will be possible to avoid inappropriate comparisons across studies. We considered other types of bias, depending on the type of study involved, including compliance bias if the intervention or control group involved self initiated patient testing, which can lead to outcomes driven by how compliant participants are, rather than how effective the screening intervention is found to be (Fletcher 2005). We assessed studies on an individual basis for other potential sources of bias.

\section{Measures of treatment effect}

We measured the effect of systematic screening by determining the difference in the number of cases of AF detected between control and intervention groups divided by the number of participants in each group. We expressed differences as the overall magnitude of the difference in AF detection rate between intervention and control or pre-intervention groups, as well as the number needed to screen (NNS) to detect one additional case of AF within the population.

We planned to carry out pooled analysis of treatment effect by using standard meta-analytical techniques, provided we obtained sufficient study data, while taking account of heterogeneity between studies. We planned to perform a fixed-effect model meta-analysis initially, with the option of using random-effects model meta-analysis if we observed a moderate or high degree of heterogeneity between studies. As a summary measure of effectiveness, we calculated odds ratios (ORs) with 95\% confidence intervals (Cls) for dichotomous variables.

\section{Unit of analysis issues}

We assessed cluster-randomised trials to ensure that appropriate analysis was carried out to address cluster effects and to avoid overestimation of the significance of differences. For clusterrandomised studies in which the analysis was carried out as if randomisation was performed on individuals rather than clusters, we made efforts to obtain the data needed to correct for this, as described in section 16.3.4 of the Cochrane Handbook for Systematic Reviews of Interventions (Higgins 2011). For randomised controlled trials that compared more than one screening method, we planned to perform the meta-analysis of each method separately to avoid counting the control group twice.

\section{Dealing with missing data}

We contacted lead investigators or corresponding authors to request missing data or additional clarification.

\section{Assessment of heterogeneity}

We planned to assess the heterogeneity of included studies if sufficient data were available to perform a meta-analysis. We considered $1^{2}$ values above $75 \%$ to have exceeded the level of heterogeneity appropriate for drawing meaningful conclusions from pooled data. We planned to perform $\mathrm{Chi}^{2}$ tests for heterogeneity and considered data heterogeneous with $\mathrm{P}$ value < 0.10 . We planned to investigate significant statistical heterogeneity, along with clinical heterogeneity of populations across included studies.

\section{Assessment of reporting biases}

We assessed studies to check whether all relevant outcomes in the study protocol were reported in the final results, using the risk of bias heading 'selective outcome reporting'. We determined that any outcomes specified in the methods that were omitted from the results would provide evidence that outcomes were selectively reported. If we found evidence of selective reporting, we planned to contact study authors to enquire whether the results were reported elsewhere (i.e. published in another paper or otherwise available). We would regard asymmetry of the funnel plot based on data for the primary outcome as an indication of publication bias.

\section{Data synthesis}

We provided a narrative of the results of included studies, along with information on their risk of bias. We planned to perform a meta-analysis of similar studies to produce a combined estimate of effect if we identified multiple studies, subject to acceptable levels of statistical and clinical heterogeneity. Differences between the results of fixed-effect and random-effects model meta-analysis would require re-examination of the clinical and methodological diversity of pooled studies before we would make a judgement regarding the most appropriate statistical model to use. In the event that available data were insufficient to perform a metaanalysis, we planned to individually report effect sizes and confidence intervals of each outcome from the included study. 


\section{Subgroup analysis and investigation of heterogeneity}

We planned to perform subgroup analysis on the following groups subject to the availability of sufficient data.

- Over 65 years of age.

- 65 to 75 years versus $>75$ years of age.

- Men versus women.

- Different ethnic groups, if reported.

- Different socioeconomic groups, if reported.

- Community versus specialist setting.

We identified subgroups a priori on the basis of a plausible rationale, supported, when possible, by published literature. We kept the number of subgroups to a minimum and assigned priority to subgroups of specific interest to the potential implementation of a systematic screening programme.

The primary subgroup examination involved effectiveness of the intervention in those over 65 years of age. The comparator for this subgroup consisted of people over 65 years of age for whom no screening programme was introduced. This group is of relevance for two reasons. First, one of the features of an ideal screening programme in primary care is that prevalence of the disease in the screened population is sufficiently high to justify screening (Goroll 1995). The prevalence of AF increases substantially with age (Feinberg 1995; Go 2001; Wolf 1991). The median age of AF patients is 75 years, and $70 \%$ are between 65 and 85 years old. Therefore, a screening programme for this group is likely to be more effective given the higher baseline prevalence of the condition compared with the overall population included in the review. The second reason why the over 65 age group is important is that they constitute a recognised group within most public health systems, thus providing an opportunity to capitalise on existing structures to effectively target a public health initiative such as a screening programme.

Given the increasing prevalence of AF with advancing age, it may be logical to assume that the older the age group targeted by the screening programme, the more effective the programme will be. To investigate this issue, we conducted a separate subgroup analysis of people 65 to 75 years of age versus those older than 75 years to compare the effectiveness of systematic screening in an older population within the group for which screening is most likely to be implemented in practice (i.e. all over 65 years).

We examined the effectiveness of systematic screening in men versus women in the subgroup analysis because it has been suggested that gender could influence the effectiveness of a screening programme for AF. Men are 1.5 times more likely than women to develop the disease (Benjamin 1994), and this may make screening in men more effective, given the higher underlying prevalence. In addition to this are factors related to potential differences in the uptake of any screening programme among men and women that could impact outcomes. The direction of this effect is uncertain. It has been reported that men are more reluctant than women to contact their GPs and other healthcare service providers (Peate 2004). Another study in the USA (CDC 2001) found that despite excluding pregnancy-related visits, women were $33 \%$ more likely than men to visit a doctor, although this difference decreased with age. However, others (Friedemann-Sanchez 2007; Wardle 2005) have reported that men are more likely to attend colorectal cancer screening than women. As the rate of uptake of screening is such an important factor in determining the success of a screening programme (Barratt 2002; Parkin 2008), it is worthwhile to separately investigate differences in outcomes reported for men and women.

Apart from gender, ethnicity and social deprivation are the two main factors found to influence population-based cancer screening programmes in the UK (Weller 2009). This review had planned to include subgroup analyses of the effectiveness of screening in different ethnic and socioeconomic groups, if these were reported, to provide useful data that could be relevant to readers of the review. This plan involved risks in that the practice of including data on outcomes only if they are reported can lead to the introduction of bias, as significant results are more likely to be published than non-significant results. However, it was anticipated that, because of the established importance of these factors, data on ethnicity and socioeconomic status would more than likely be reported for large population-based screening programmes, in which it is appropriate and is unlikely to be reported in studies for which the participant population or screening approach is incompatible with such an analysis. Despite this, we had planned to clearly explain the limitations of available data and the caveats associated with subgroup interpretation in the reporting of the review, had it been possible to conduct this analysis.

The final subgroup that was to be examined involves the setting within which the screening programme was conducted. Studies of screening strategies carried out within the community or in primary care could have been identified, along with studies based in specialist settings such as hospitals or other secondary care facilities. Given the importance of the setting to any consideration of how a major screening programme could be implemented within a health system, we considered it important to provide an analysis of any differences in reported outcomes associated with the setting. The setting could affect how well a screening programme performs in several ways. The acceptability of clinical settings in which systematic screening takes place to the person to whom the test is offered can affect rate of uptake; settings within the community, such as GP- or public health nurse-led programmes, may be more acceptable, and therefore more effective, for people who are used to receiving care in these settings. As with ethnicity and socioeconomic subgroups, we planned to perform these subgroup analyses only if we considered it appropriate to do so after considering the studies included in the review.

\section{Sensitivity analysis}

Depending on the studies identified through the systematic search, we planned to conduct a sensitivity analysis to calculate the effect of risk of bias within studies on effect size by calculating the effects of excluding or including studies with higher risk of bias.

\section{RE S U L T S}

\section{Description of studies}

One cluster-randomised controlled trial (cluster-RCT) met the inclusion criteria (Hobbs 2005). We also identified two potentially relevant studies that are currently ongoing (NCT01593553; NCT01291953). 


\section{Results of the search}

We identified 23,506 citations during the search. After removal of duplicates and screening out of irrelevant studies, two review authors (PM and CT) independently reviewed 181 citations and found one unique study citation that met the inclusion criteria
(Hobbs 2005). See Figure 1 for additional details. We contacted seven study authors during the review process to enquire whether they had conducted additional research in this area since the time of publication of their last article, or if they knew of other studies that may be eligible for inclusion. Despite a high rate of response (5/7), we identified no additional studies. 
Figure 1. Study flow diagram.

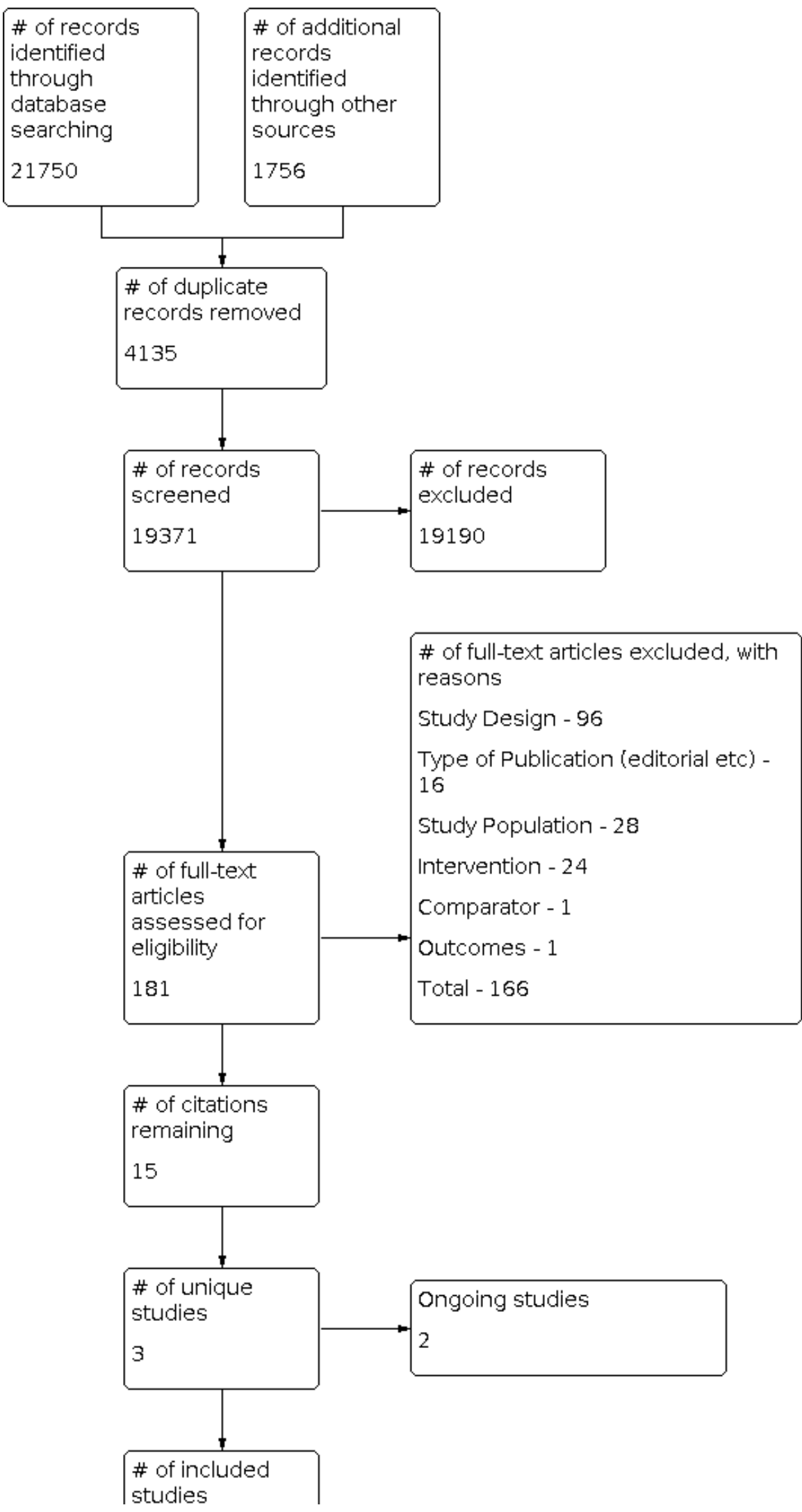


Figure 1. (Continued)

$$
\begin{aligned}
& \text { \# of included } \\
& \text { studies } \\
& 1
\end{aligned}
$$

\section{Included studies}

The single study that met the inclusion criteria for this review was a cluster-randomised trial comparing screening of those 65 years of age or older versus routine practice in the primary care setting in the UK (Hobbs 2005). Investigators randomised 25 general practices with computerised record keeping systems to control or intervention groups, stratifying randomisation according to practice size and level of deprivation (Townsend score). All practices within the intervention group received educational materials highlighting the importance of AF detection and the range of available treatment options. Healthcare professionals within these practices were encouraged to consider opportunistic pulse taking during routine consultation. In total, investigators randomly selected 10,000 patients 65 years of age or older from the intervention practices and allocated them equally between two different screening interventions embedded within the intervention arm. These groups underwent systematic screening, whereby patients were invited by letter to attend an ECG screening clinic, or opportunistic screening, when patients' GP records were flagged to prompt the GP to check pulse whenever that patient next attended the practice for any reason. Healthcare professionals in control practices received no training; 5000 patients 65 years of age or older were randomly selected from this group for follow-up as a comparator group receiving routine care.

\section{Excluded studies}

Fifteen studies examining screening for AF did not meet the inclusion criteria for this review (ACTRN12612000406808; Baxter 1998; Claes 2012; DeRuijter 2008; Ho 2004; Hoefman 2005; Johnson 2010; Maeda 2004; Marek 2011; Morgan 2002; Munschauer 1999; Somerville 2000; Sudlow 1998; Wheeldon 1998; Wright 2007). We have described the reasons for their exclusion in the Characteristics of excluded studies section.

\section{Risk of bias in included studies}

As only one study met the inclusion criteria, we have limited this review to summarising risk of bias for that study across outcomes, with particular reference to the primary outcome of differences in the rate of detection of AF. We have provided in Figure 2 a summary of the risk of bias assessment. 
Figure 2. Risk of bias summary: review authors' judgements about each risk of bias item for each included study.

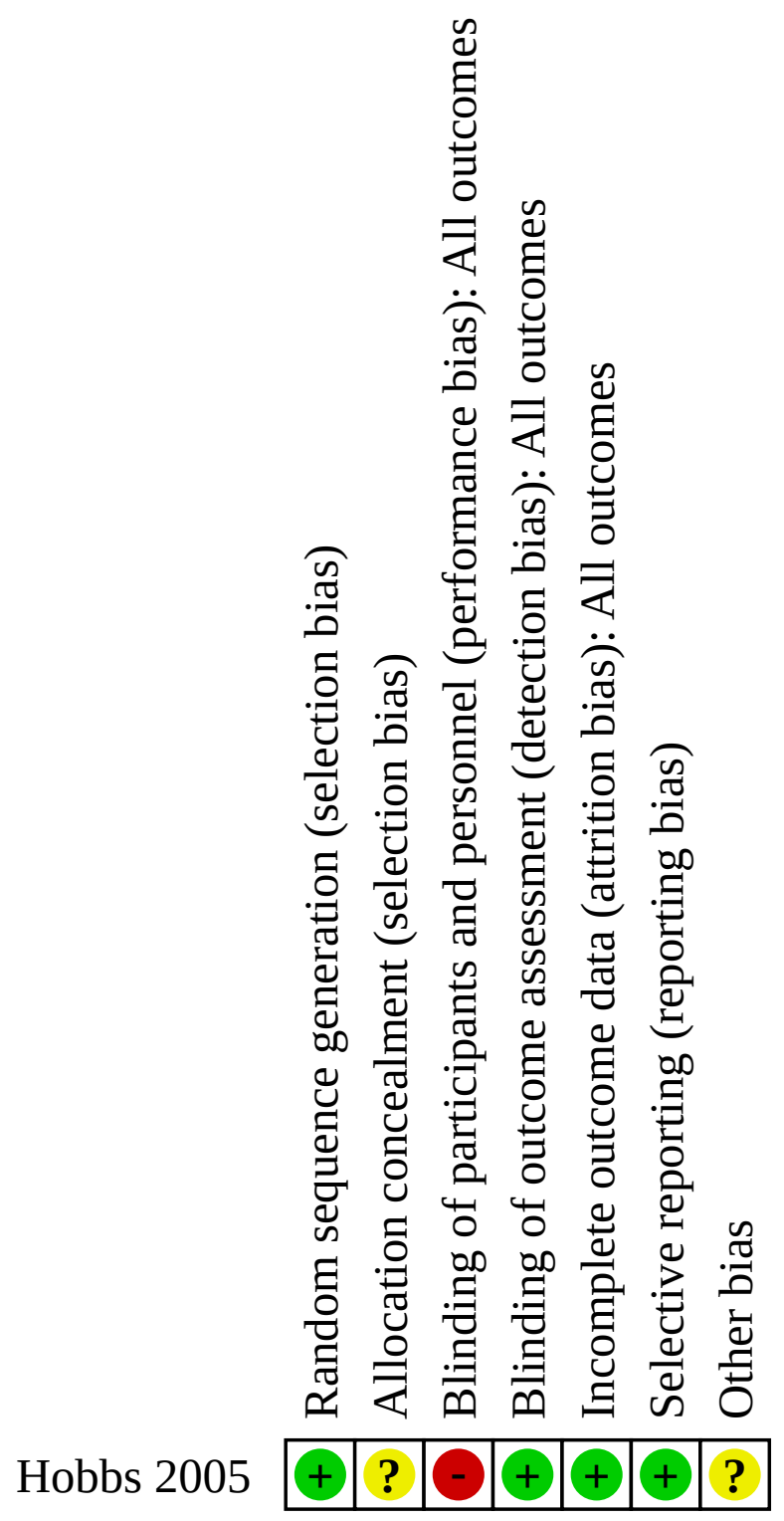

\section{Allocation}

Randomisation methods used to allocate participants in the included study resulted in low risk of bias because all centres were randomised at the same time, and intervention and control groups were not known at the point of randomisation. Within the treatment group, participants were selected by computergenerated random numbers, and lists were stratified on the basis of numbers of participants with an existing diagnosis of AF, which resulted in each arm having a comparable chance of detecting known, unknown or suspected AF. Allocation to trial arms was not deliberately concealed, but clusters (GP practices) were identified and recruited before randomisation was conducted, so allocation was concealed from the people providing permission for the cluster to be included in the trial. Similarly, participants in the intervention arm were identified and randomly allocated to two groups before it was known to anyone involved in the trial which group would be allocated to which treatment (opportunistic or systematic). However, as no deliberate attempt was made to conceal allocation, it remains unclear to what extent risk of selection bias might have arisen from awareness of individuals in the intervention arm that they were in the intervention arm - not the control arm - before 
participants were recruited. See the Characteristics of included studies table for more information.

A separate issue is the potential for self selection bias inherent in screening studies in which participants decide whether or not to undergo testing. However, given the randomisation methods used and the intention-to-treat analysis performed, the risk of bias associated with this is considered to be low.

\section{Blinding}

Given the nature of the intervention, it was not possible to blind participants in the included study. In the systematic screening arm, participants were invited to attend an ECG clinic. One of the factors contributing to the outcome of the intervention was the rate of uptake of this invitation; this decision had to be made by individual participants who were provided adequate information to make an informed decision. In the opportunistic screening arm, participant records were flagged to prompt clinicians to offer to palpate the pulse of those who presented to the GP practice for any reason. In this arm, participants also needed to be informed about the intervention and to decide whether or not to participate. Therefore, blinding of participants and GPs as a method of reducing the likelihood of performance bias was neither achievable nor desirable given the intervention. See the Characteristics of included studies table for more information.

Detection bias was minimised by blinding the two consultant cardiologists who read the 12-lead ECGs to whether ECGs were those of participants who had received an invitation for screening $(n=2357)$ or participants referred after detection of an irregular pulse $(n=238)$. All ECG tracings were taken by practice nurses who probably were not blinded to the treatment arm of individual participants.

\section{Incomplete outcome data}

We noted a significant difference in the numbers of participants excluded by GPs from the systematic and opportunistic arms of the trial following randomisation. Five hundred participants $(10.1 \%)$ in the systematic arm and $195(4 \%)$ in the opportunistic arm had died, had moved away from the practice area or were terminally ill or otherwise unsuitable for screening. The risk of bias associated with this was low, however, because the same criteria were used to exclude participants in both arms of the intervention, and $98 \%$ of withdrawals from the systematic group occurred because participants had died (246 participants) or had moved away (245 participants). We used an intention-to-treat analysis to calculate differences in the rate of detection of new cases of AF between different arms, including the number of participants in each arm before these withdrawals occurred. We excluded from the calculation only participants with a pre-existing diagnosis of AF $(7.2 \%)$ and those whose notes were missing (0.6\%). See the Characteristics of included studies table for more information.

Researchers searched the notes of all participants within each group at the end of the study to identify those who had been diagnosed with AF over the course of the trial, including participants in the intervention groups who had been diagnosed outside the screening programme. We included these diagnoses in the analysis of the primary outcome.

\section{Selective reporting}

We found no suggestion of selective reporting in the included study. Investigators reported all outcomes specified in the trial protocol (Swancutt 2004).

\section{Other potential sources of bias}

Unclear risk of recruitment bias emanated from the fact that after initial randomisation, lists of participants were given to GPs to exclude those unsuitable for screening to replace them from a back-up list that had been generated as part of the original randomisation process. No data were provided on the numbers from each group replaced at this stage. GPs were instructed to remove people who had died, had moved away or were terminally ill. Significant differences in the numbers excluded from each arm may have indicated differences in the way these criteria were applied by practice GPs across the two groups, potentially introducing bias. Data generated by the second round of exclusions, which was performed immediately before screening, resulted in the removal of $10 \%$ of people from the systematic arm compared with 4\% from the opportunistic arm (see Incomplete outcome data (attrition bias) section above).

\section{Effects of interventions}

See: Summary of findings 1 Screening versus routine practice for detection of atrial fibrillation; Summary of findings 2 Systematic screening versus opportunistic screening for detection of atrial fibrillation

For the primary outcome of detection of new cases of AF, results from the single included study show that both systematic screening and opportunistic screening of people over the age of 65 years for AF in primary care were more effective than routine practice (OR $1.57,95 \% \mathrm{Cl} 1.08$ to 2.26 ; moderate-quality evidence, Analysis 1.1; and OR 1.58, 95\% Cl 1.10 to 2.29; moderatequality evidence, Analysis 1.2, respectively). Investigators found no significant differences between systematic and opportunistic screening in terms of the number of new cases detected (OR $0.99,95 \% \mathrm{Cl} 0.72$ to 1.37 ; low-quality evidence, Analysis 2.1). The number needed to screen to detect one additional case compared with routine practice was $172(95 \% \mathrm{Cl} 94$ to 927$)$ for systematic screening and 167 (95\% Cl 92 to 806) for opportunistic screening. When gender subgroups were analysed, results indicated that both systematic screening and opportunistic screening were more effective in men (OR 2.68, $95 \% \mathrm{Cl} 1.51$ to 4.76 ; and OR 2.33, 95\% $\mathrm{Cl} 1.29$ to 4.19 , respectively) than in women (OR $0.98,95 \% \mathrm{Cl} 0.59$ to 1.62 ; and $\mathrm{OR} 1.2,95 \% \mathrm{Cl} 0.74$ to 1.93 , respectively, Analysis 1.3 and Analysis 1.5). The difference between gender subgroups was statistically significant for systematic screening $\left(\mathrm{Chi}^{2}=6.64, \mathrm{P}\right.$ value $\left.=0.01, \mathrm{I}^{2}=84.9 \%\right)$ but not for opportunistic screening $\left(\mathrm{Chi}^{2}=2.95\right.$, $\mathrm{P}$ value $=0.09, \mathrm{I}^{2}=66.1 \%$ ). Subgroup analysis by age ( 65 to 74 years, 75+) failed to show significant differences in the detection of new cases of AF between participants in these two age ranges (Analysis 1.4 and Analysis 1.6). See Table 1 for the numbers of new cases of AF diagnosed in each group and by gender and age group. No data were reported on different ethnic groups. No association between socioeconomic status and effectiveness of systematic or opportunistic screening was reported.

Acceptability of the screening intervention was measured by the rate of uptake of screening, feedback from participants and health professionals and costs associated with screening from the point of 
view of the participant. For systematic screening, an invitation was considered accepted if the participant attended an ECG screening clinic after receipt of the letter. For opportunistic screening, a participant was considered to have participated in the programme if he or she agreed to have pulse taken opportunistically during a routine consultation and subsequently accepted an offer of an ECG if an irregular pulse was found. This differed from the analysis carried out within the included study, which considered uptake on the basis of those who agreed to have their pulse taken, even if they declined to have an ECG if an irregular pulse was found. The rationale for taking a different approach in this review was that because ECG confirmation was required to make a diagnosis, participants for whom this was indicated who did not proceed to have an ECG could not be said to have taken up the offer of screening because they had not completed the full twostage process. Uptake results are shown in Table 2. Systematic screening was associated with a greater overall rate of uptake than opportunistic screening, with a higher rate of uptake of systematic screening seen in both men and women. This trend was also observed in the 65 to 74 year age group, but for those over 75 years of age, uptake rates for both interventions were similar. Overall, men were more likely to participate in screening than women, and people from the younger age group ( 65 to 74 years) were more likely to participate than those 75 years of age and older. A questionnaire concerning the acceptability of screening was administered to all participants undergoing an ECG within the intervention arm: 95\% of those who completed this felt that screening was important (1810/1897); 17\% (324/1897) felt they did not know what was involved; and 4\% (70/1897) felt that screening was not convenient. Mean costs incurred by patients undergoing ECG were GBP 3.13 (95\% $\mathrm{Cl} 2.97$ to 3.29 , range GBP 0.65 to 14.53 ).

No specific adverse events associated with screening were reported. Anxiety levels and quality of life were measured at baseline and at the end of the study with the six-item Spielberger State Anxiety Inventory and the five-item EQ-5D. A total of 750 questionnaires were distributed to participants in the intervention arm before screening. A total of 620 were returned: 311 from opportunistic participants (55 not completed) and 309 from systematic participants (72 not completed). No significant difference was found between the two intervention arms at baseline for anxiety $(z=-0.392, P$ value $=0.695)$ or quality of life $(z=-0.334, P$ value $=0.739)$. A total of 777 post-screening questionnaires were distributed, and 630 were returned, 535 of which were completed: 479 participants completed the six-item Spielberger State Anxiety Inventory, and 520 competed the fiveitem EQ-5D. No significant difference was found between the two intervention arms at the end of the study for anxiety $(z=-1.699$, $P$ value $=0.089)$ or quality of life $(z=-1.166, P$ value $=0.244)$. End of study anxiety scores for screen-positive and screen-negative participants were significantly different $(F(1268)=4.883$, $P$ value $=$ 0.028 ). Participants diagnosed with AF had a higher anxiety score (38.12, $95 \% \mathrm{Cl} 35.89$ to 40.35 vs $34.61,95 \% \mathrm{Cl} 32.41$ to 36.81 ) and a lower quality of life score $(0.66,95 \% \mathrm{Cl} 0.59$ to 0.70 vs $0.73,95 \% \mathrm{Cl}$ 0.68 to 0.77$)$.

An economic analysis carried out as part of the single included study found that when costs were examined from the perspective of a national health service provider (National Health Service (NHS), in this case), the incremental cost of the estimated 28 additional cases detected via opportunistic screening compared with no screening was GBP 9429 (95\% Cl 8938 to 9920), yielding an incremental cost per additional case detected of GBP 337. The incremental cost of the estimated 27 additional cases detected using systematic screening compared with no screening was GBP 40,882 (95\% Cl 39,790 to 41,974 ), yielding an incremental cost per additional case detected of GBP 1514. All cost estimates were based on trial data, and the trial was conducted in the UK between 2001 and 2003.

Atrial fibrillation prevalence results from the included study are presented in Table 3. This table shows baseline and 12-month prevalence of $\mathrm{AF}$ within the study population in control and intervention arms, with a breakdown of prevalence by gender and age group ( 65 to 74,75 to $84, \geq 85$ years).

Data were insufficient to compare effectiveness of screening programmes in different healthcare settings.

\section{I S C U S S I O N}

\section{Summary of main results}

Only one study met the eligibility criteria for this review (Hobbs 2005). We identified no studies examining screening in populations younger than 65 years. We identified two ongoing studies that are likely to be of relevance to this review in the future (NCT01593553; NCT01291953). On the basis of results of one included study, this review found moderate-quality evidence that both systematic screening and opportunistic screening increase the rate of detection of AF in people 65 years and older compared with routine practice. Low-quality evidence showed no significant difference in relative effectiveness between the two interventions, with approximately 170 participants needing to be screened in both groups to detect one additional case. Uptake rates were higher for systematic screening than for opportunistic screening. Given the additional resources needed to support populationbased systematic screening, the overall cost of this intervention is considerably greater than that of opportunistic screening.

\section{Overall completeness and applicability of evidence}

The single identified study provides evidence on the effectiveness of screening for AF in people over 65 years of age, the acceptability of this intervention in the target population and costs associated with the intervention within a publicly funded primary care setting. However, few studies have examined other potential screening strategies, younger populations and different healthcare settings.

Acceptability of the intervention is a key factor in its effectiveness; therefore, differences with regard to participation rates, a patient's perception of screening and direct costs to patients in different settings mean that caution must be exercised in relation to the transferability of results. We calculated the uptake rate in the overall study population for opportunistic screening on the basis of the numbers of participants who agreed to have their pulse taken and to have an ECG if an irregular pulse was found; $34 \%$ of those found to have an irregular pulse declined an ECG and therefore were not considered to have been opportunistically screened because they did not complete the intervention. In the group that did not consent to an ECG, 46\% (56/122) already had a diagnosis of AF. When only those without a baseline diagnosis of AF were used to calculate uptake, the percentage of participants discovered to have an irregular pulse who declined an ECG was $27 \%$. Reasons for such a high dropout rate between irregular pulse finding and ECG remain unknown. If the uptake rate is calculated solely on the basis of a patient consenting to have pulse taken opportunistically 
during a routine consultation, then the uptake rate increases to $69 \%$. Although low levels of uptake and completion of screening represent a cause for concern, the uptake rate of the included study is high when compared with an earlier study within the same health system comparing systematic screening (via invitation to attend nurse-led pulse palpation) versus opportunistic screening (Morgan 2002); this study recorded an uptake rate of $29 \%$ in the opportunistic arm based on those who presented for any reason and consented to have their pulse taken regardless of whether or not an ECG was subsequently used to confirm the diagnosis. Hobbs 2005 concluded that these differences in uptake were due to improved coverage attained over the 12-month period of the Hobbs 2005 study, compared with the Morgan 2002 study, which ran over six months. An excluded study (Wheeldon 1998), which was also conducted in the primary care setting in England, invited all patients 65 years of age and older to have a 12-lead ECG to screen for AF and reported an uptake rate of $85 \%$. The uptake rate of ECG screening reported in this study, which was excluded because of the absence of a comparison group receiving routine care, differs considerably from that of the systematic screening arm in Hobbs 2005 , which achieved an uptake rate of $53 \%$. These differences provide an indication of the variability that can exist within and between different screening strategies.

Another factor requiring consideration is the percentage of diagnoses made outside of actual screening programmes within the intervention arm in Hobbs 2005. Of 74 new cases of $A F$ identified in the systematic group, 22 (30\%) were diagnosed outside the screening programme over the 12 months of the study. For opportunistic screening, a greater proportion of the 75 newly identified cases were diagnosed outside the screening programme $(44 / 75,59 \%)$ than within it $(31 / 75,41 \%)$. When calculations were based only on participants who received the screening intervention, systematic screening had a detection rate of $2.2 \%$ compared with $0.9 \%$ for opportunistic screening. This implies a detection rate for those who did not participate in screening of $1 \%$ and $3 \%$ for systematic and opportunistic groups, respectively. The detection rate among non-participants in the systematic arm is similar to that observed in the control arm (both approximately 1\%) - a figure that contrasts with the significantly higher detection rate seen among non-participants in the opportunistic arm (approximately 3\%). Reasons for these differences are unclear, but they do have potential implications for service providers considering introducing AF screening and determining how such services should be evaluated after their introduction.

Subgroup analysis of data from the single included study indicate that the effectiveness of both screening interventions is different among men and women. When male and female subgroups were analysed separately, both systematic screening and opportunistic screening continued to show a significant effect on new case detection compared with routine practice in men. No differences between either systematic or opportunistic screening and routine practice were seen in the subgroup of women. Possible reasons for this include differences in the prevalence of $\mathrm{AF}$ among men and women, differences in the rate of uptake or differences in overall numbers in each group, which would result in under-powering of subgroups to detect significant effects. However, this study included more women than men in both intervention groups (1958 men vs 2604 women in the systematic group; 1941 men vs 2634 women in the opportunistic group; 1880 men vs 2633 women in the control group), so the female subgroup was better powered to detect differences. However, although the study included more women, it was still underpowered to detect effect sizes of the magnitude seen in the overall study within the subgroup of women. The rate of uptake of screening was higher among men than women ( $57 \%$ vs $50 \%$ for systematic; $49 \%$ vs $41 \%$ for opportunistic), although more women agreed to have their pulse taken in the opportunistic arm (71\% vs $67 \%$ ). A higher prevalence of AF in men than in women has been consistently shown (Gowd 2012), and this is borne out in the baseline prevalences reported in this study $(7.8 \%$ in males, $6.8 \%$ in females). Therefore, differences in effect observed between subgroups of men and women could be due to a combination of higher prevalence and a greater rate of participation among men. This finding may have implications for the provision of AF screening programmes.

Other factors that may affect transferability of these results include direct patient costs associated with screening (which can affect uptake) and prevalence of undiagnosed AF. Although direct costs to patients are low in a publicly funded screening programme, the coverage achievable with opportunistic screening when GP care is not provided free at the point of use may be lower than that reported in the included study, and funding models that subsidise GP care for a proportion of the population may influence who benefits from screening (McGregor 2006). Within the NHS, financial incentives introduced since the completion of this study through the Quality and Outcomes Framework (QoF), which encourage GPs to diagnose AF, may limit the effectiveness of screening compared with no screening because the prevalence of undiagnosed AF may be lower now than in 2003, when this research was carried out. In addition, this type of incentive may prove more effective than a screening programme in terms of identifying cases of $\mathrm{AF}$, or may alter the delivery and uptake of screening programmes. These issues need to be taken into account when applicability of these results within a given healthcare setting is considered.

The study that met the inclusion criteria for this review compared systematic screening via an invitation to attend an ECG clinic, and opportunistic screening via pulse palpation during routine consultations. However, a range of other strategies could be used to screen for the arrhythmia in a variety of settings. As no studies comparing these with routine practice were identified, this review is limited in terms of the screening interventions that could be compared. Alternative screening strategies that have been described in excluded studies include use of self screening methods (Baxter 1998; Munschauer 1999), populationbased screening programmes using a national media campaign to invite participants (Claes 2012), systematic screening whereby patients are invited for pulse palpation rather than an ECG (Morgan 2002) and opportunistic ECG recording (Caldwell 2012).

\section{Quality of the evidence}

We assessed the quality of evidence using the GRADE (Grades of Recommendation, Assessment, Development and Evaluation Working Group) approach. For comparison of both systematic screening and opportunistic screening with routine care, we judged the evidence to be of moderate quality, primarily because of risk of bias due to the fact that given the nature of the intervention, it was not possible to blind participants. For the comparison of systematic screening versus opportunistic screening, we judged the evidence to be of low quality because of risk of bias resulting from inability to blind participants and imprecision of this result, which has wide 
confidence intervals that crossed the line of no effect. See Summary of findings 1 and Summary of findings 2 for more information.

\section{Potential biases in the review process}

We carried out a comprehensive search to identify randomised controlled trials (RCTs) that compared screening for AF versus routine practice in a general population of people over 40 years of age. We contacted authors of relevant published or ongoing studies to enquire about other studies in this area. Only one cluster-RCT met the inclusion criteria, and the population included in this study was 65 years of age or older. We did not require the input of a third review author to settle disagreements concerning inclusion of individual studies, and two review authors (PM and CT) crosschecked data from the included study. We considered risk of bias in the review process to be low.

\section{Agreements and disagreements with other studies or reviews}

A review of strategies for the detection of AF (Harris 2012) identified two studies (Hobbs 2005; Morgan 2002) examining the effectiveness of screening. Conclusions are consistent with those of Hobbs 2005, which recommended opportunistic screening in the general population and highlighted that although a 12-lead ECG remains the standard investigation, the cost-effectiveness of newer technologies requires further research.

The overall rate of detection of new cases of AF in both intervention groups and the control group in the Hobbs 2005 study was approximately $1.6 \%$ and $1 \%$, respectively. Two studies excluded because of the absence of a control arm in the study design also reported the rate of detection of new cases of AF over the course of the study. Morgan 2002 reported a new case detection rate of $0.8 \%$ for systematic screening via an invitation to attend nurseled pulse palpation and $0.4 \%$ for opportunistic pulse palpation, whereas Wheeldon 1998 reported a detection rate of $0.8 \%$ for systematic screening via an invitation to undergo a 12-lead ECG. Although these studies could not be included in this review, they provide some context in relation to the level of variability that exists between studies in this area.

\section{AUTHORS' CONCLUSIONS}

\section{Implications for practice}

Moderate-quality evidence suggests that both systematic screening and opportunistic screening increase the rate of detection of new cases of atrial fibrillation (AF) compared with routine practice in people over the age of 65 years in a primary care setting. In the absence of additional data, caution must be exercised in drawing conclusions about the relative effectiveness of systematic and opportunistic screening. The included study provides low- quality evidence that both approaches have a comparable effect on the overall AF diagnosis rate, with the cost of systematic screening significantly greater than that of opportunistic screening from the perspective of the health service provider. The potential contribution of the educational element of the intervention that occurred in both systematic and opportunistic screening arms before the time of screening should not be overlooked. This may have influenced the number of new cases detected outside the screening programmes in both arms - something that was particularly important in the opportunistic screening group, where $59 \%$ of new diagnoses were made outside the screening programme itself. Systematic screening achieves a higher uptake rate than opportunistic screening because about a third of people found to have an irregular pulse when opportunistically screened decline a confirmatory electrocardiogram (ECG) test. This may pose ethical issues with regard to treatment of patients for whom an irregular pulse is recorded but ECG confirmation is absent. Available evidence indicates that screening offered to males is more effective than screening offered to females compared with routine practice. The small number of studies investigating effects of screening in other health systems and in younger age groups indicate that caution must be exercised in relation to transferability of these results beyond the setting and population in which the study was conducted.

\section{Implications for research}

Two ongoing trials may provide additional data relevant to this review question (NCT01291953; NCT01593553). Future studies should examine the effect of using different types of ECG technology and different readers, which may have important implications for both clinical outcomes and cost-effectiveness of systematic and opportunistic screening. In addition, highquality studies examining the effectiveness of alternative screening strategies (e.g. opportunistic ECG, self screening) would expand the evidence base for this topic. Further research is also needed to investigate the effects of screening on clinical outcomes such as stroke, and in particular the effectiveness of anticoagulation in screen-detected versus non-screen-detected patients.

\section{ACKNOWLEDGEMENTS}

We would like to acknowledge the following.

- The Health Research Board (HRB), which funded a Cochrane Fellowship for Patrick Moran.

- The Health Information and Quality Authority, which provided support for performance of this review.

- The Cochrane Heart Group, which provided ongoing advice and support in writing the protocol, developing the search strategy and running the search. 


\section{R E F E R E N C E S}

\section{References to studies included in this review}

Hobbs 2005 \{published data only\}

Fitzmaurice DA, Hobbs FD, Jowett S, Mant J, Murray ET, Holder R, et al. Screening versus routine practice in detection of atrial fibrillation in patients aged 65 or over: cluster randomised controlled trial. BMJ 2007;335(7616):383.

Hobbs FDR, Fitzmaurice DA, Jowett S, Mant J, Murray E, Bryan S, et al. A randomised controlled trial and cost-effectiveness study of systematic screening (targeted and total population screening) versus routine practice for the detection of atrial fibrillation in people aged 65 and over. The SAFE study. Health Technology Assessment 2005;9:40.

Mant J, Fitzmaurice DA, Hobbs FD, Jowett S, Murray ET, Holder R, et al. Accuracy of diagnosing atrial fibrillation on electrocardiogram by primary care practitioners and interpretative diagnostic software: analysis of data from screening for atrial fibrillation in the elderly (SAFE) trial. BMJ 2007;335(7616):380

Swancutt D, Hobbs R, Fitzmaurice D, Mant J, Murray E, Jowett S, et al. A randomised controlled trial and cost effectiveness study of systematic screening (targeted and total population screening) versus routine practice for the detection of atrial fibrillation in the over 65s: (SAFE) [ISRCTN19633732]. BMC Cardiovascular Disorders 2004;4:12.

\section{References to studies excluded from this review}

ACTRN12612000406808 \{published data only\}

Freedman B. Screening Education And Recognition in Community pHarmacies of Atrial Fibrillation to prevent stroke (SEARCH-AF). Australian New Zealand Clinical Trials Registry 2012;Trial Identifier: ACTRN12612000406808.

\section{Baxter 1998 \{published data only\}}

Baxter J, Crabtree L, Hildreth A, Gray C, O'Connell J. Atrial fibrillation. Lancet 1998;352(9143):1858.

\section{Bury 2015 \{published data only\}}

Bury G, Swan D, Cullen W, Keane D, Tobin H, Egan M, et al. Screening for atrial fibrillation in general practice: a national, cross-sectional study of an innovative technology. International Journal of Cardiology 2015;178:247-52.

\section{Claes 2012 \{published data only\}}

Claes N, Van Laethem C, Goethals M, Goethals P, Mairesse G, Schwagten $B$, et al. Prevalence of atrial fibrillation in adults participating in a large-scale voluntary screening programme in Belgium. Acta Cardiologica 2012;67(3):273-8.

\section{DeRuijter 2008 \{published data only\}}

De Ruijter W, Assendelft WJ, Macfarlane PW, Westendorp RG, Gussekloo J. The additional value of routine electrocardiograms in cardiovascular risk management of older people.

Scandinavian Journal of Primary Health Care 2008;26(3):147-53.
Ho 2004 \{published data only\}

Ho SF, O'Mahony MS, Steward JA, Burr ML, Buchalter M. Left ventricular systolic dysfunction and atrial fibrillation in older people in the community--a need for screening? Age and Ageing 2004;33(5):488-92

Hoefman 2005 \{published data only\}

Hoefman E, van Weert HC, Reitsma JB, Koster RW, Bindels PJ. Diagnostic yield of patient-activated loop recorders for detecting heart rhythm abnormalities in general practice: a randomised clinical trial. Family Practice 2005;22(5):478-84.

\section{Johnson 2010 \{published data only\}}

Johnson BJ, Urrutia V. Stroke risk factor screening in an inner city public market - A description of the population - A better target for screening/education efforts. Stroke 2010;41:e200-53.

\section{Maeda 2004 \{published data only\}}

Maeda K, Shimbo T, Fukui T. Cost-effectiveness of a communitybased screening programme for chronic atrial fibrillation in Japan. Journal of Medical Screening 2004;11(2):97-102.

\section{Marek 2011 \{published data only\}}

Marek J, Bufalino V, Davis J, Marek K, Gami A, Stephan W, et al. Feasibility and findings of large-scale electrocardiographic screening in young adults: data from 32,561 subjects. Heart Rhythm 2011;8(10):1555-9.

\section{Morgan 2002 \{published data only\}}

Morgan S, Mant D. Randomised trial of two approaches to screening for atrial fibrillation in UK general practice. The British Journal of General Practice 2002;52(478):373-4, 377-80.

\section{Munschauer 1999 \{published data only\}}

Munschauer FE, Hens MM, Priore RL, Stolarski E, Buffamonte S, Carlin A, et al. Screening for atrial fibrillation in the community: a multicenter validation trial. Journal of Stroke and Cerebrovascular Diseases 1999;8(2):99-103.

Somerville 2000 \{published data only\} Somerville S, Somerville J, Croft P, Lewis M. Atrial fibrillation: a comparison of methods to identify cases in general practice. The British Journal of General Practice 2000;50(458):727-9.

\section{Sudlow 1998 \{published data only\}}

Sudlow M, Rodgers H, Kenny RA, Thomson R. Identification of patients with atrial fibrillation in general practice: a study of screening methods. BMJ 1998;317(7154):327-8.

\section{Virtanen 2014 \{published data only\}}

Virtanen R, Kryssi V, Vasankari T, Salminen M, Kivela SL, Airaksinen KE. Self-detection of atrial fibrillation in an aged population: the LietoAF Study. European Journal of Preventive Cardiology 2014;21(11):1437-42.

Wheeldon 1998 \{published data only\}

Wheeldon NM, Tayler DI, Anagnostou E, Cook D, Wales C, Oakley GD. Screening for atrial fibrillation in primary care. Heart 1998;79(1):50-5. 
Wright 2007 \{published data only\}

Wright J, Bibby J, Eastham J, Harrison S, McGeorge M, Patterson C, et al. Multifaceted implementation of stroke prevention guidelines in primary care: cluster-randomised evaluation of clinical and cost effectiveness. Quality \& Safety in Health Care 2007;16(1):51-9.

\section{References to ongoing studies}

NCT01291953 \{published and unpublished data\} NCT01291953. Effectiveness of Early Detection of Atrial Fibrillation (FAMDAP). http://www.clinicaltrials.gov/ct2/show/ NCT01291953 (accessed 24 January 2013).

\section{NCT01593553 \{published data only\}}

NCT01593553. Systematic ECG Screening for Atrial Fibrillation Among 75 Year Old Subjects in the Region of Stockholm and Halland, Sweden. http://www.clinicaltrials.gov/ct2/show/ NCT01593553?term=NCT01593553\&rank=1 (accessed 24 January 2013).

\section{Additional references}

\section{Barratt 2002}

Barratt A, Mannes P, Irwig L, Trevena L, Craig J, Rychetnik L. Cancer screening. Journal of Epidemiology and Community Health 2002;56(12):899-902.

\section{Benjamin 1994}

Benjamin EJ, Levy D, Vaziri SM, D'Agostino RB, Belanger AJ, Wolf PA. Independent risk factors for atrial fibrillation in a population-based cohort. The Framingham Heart Study. JAMA 1994;271(11):840-4.

\section{Benjamin 1998}

Benjamin EJ, Wolf PA, D'Agostino RB, Silbershatz H, Kannel WB, Levy D. Impact of atrial fibrillation on the risk of death: the Framingham Heart Study. Circulation 1998;98(10):946-52.

\section{Bilato 2009}

Bilato C, Corti MC, Baggio G, Rampazzo D, Cutolo A, Iliceto S, et al. Prevalence, functional impact and mortality of atrial fibrillation in an older Italian population (from the PRO.V.A Study). American Journal of Cardiology 2009;104:1092-7.

\section{Caldwell 2012}

Caldwell JC, Borbas Z, Donald A, Clifford A, Bolger L, Black A, et al. Simplified electrocardiogram sampling maintains high diagnostic capability for atrial fibrillation: implications for opportunistic atrial fibrillation screening in primary care. Europace 2012;14(2):191-6.

\section{CDC 2001}

CDC. Utilization of Ambulatory Medical Care by Women: United States, 1997-98. Series Report 13, No. 149, 2001. http:// www.cdc.gov/nchs/data/series/sr_13/sr13_149.pdf (accessed 18 May 2016).

\section{Cooke 2006}

Cooke G, Doust J, Sanders S. Is pulse palpation helpful in detecting atrial fibrillation? A systematic review. Journal of Family Practice 2006;55(2):130-4.

\section{Cullinane 1998}

Cullinane M, Wainwright R, Brown A, Monaghan M, Markus HS. Asymptomatic embolization in subjects with atrial fibrillation not taking anticoagulants: a prospective study. Stroke 1998;29(9):1810-5

\section{ESC 2010}

European Heart Rhythm Association, European Association for Cardio-Thoracic Surgery, Camm AJ, Kirchhof P, Lip GY, Schotten U, Savelieva I, et al. Guidelines for the management of atrial fibrillation: the Task Force for the Management of Atrial Fibrillation of the European Society of Cardiology (ESC). European Heart Journal 2010;31(19):2369-429.

\section{Feinberg 1995}

Feinberg WM, Blackshear JL, Laupacis A, Kronmal R Hart RG. Prevalence, age distribution, and gender of patients with atrial fibrillation. Analysis and implications. Archives of Internal Medicine 1995;155(5):469-73.

\section{Fitzmaurice 2007}

Fitzmaurice DA, Hobbs FD, Jowett S, Mant J, Murray ET, Holder R, et al. Screening versus routine practice in detection of atrial fibrillation in patients aged 65 or over: cluster randomised controlled trial. BMJ 2007;335(7616):383.

\section{Flegel 1987}

Flegel KM, Shipley MJ, Rose G. Risk of stroke in non-rheumatic atrial fibrillation [published erratum appears in Lancet 1987;1:878]. Lancet 1987;1:526-9.

\section{Fletcher 2005}

Fletcher RH, Fletcher SW. Clinical epidemiology: the essentials. Fourth edition. Baltimore, MD: Lippincott Williams \& Wilkins, 2005.

\section{Frazier 1990}

Frazier TG, Cummings PD. Motivational factors for participation in breast cancer screening. Journal of Cancer Education 1990;5(1):51-4.

\section{Freiberg 1997}

Friberg J, Buch P, Scharling H, Gadsbphioll N, Jensen GB. Rising rates of hospital admissions for atrial fibrillation. Epidemiology 2003;14:666-72.

\section{Friberg 2010}

Friberg L, Hammar N, Rosenqvist M. Stroke in paroxysmal atrial fibrillation: report from the Stockholm Cohort of Atrial Fibrillation. European Heart Journal 2010;31:967-75.

\section{Friedemann-Sanchez 2007}

Friedemann-Sánchez G, Griffin JM, Partin MR. Gender differences in colorectal cancer screening barriers and information needs. Health Expectations 2007;10(2):148-60. 


\section{Furberg 1994}

Furberg CD, Psaty BM, Manolio TA, Gardin JM, Smith VE, Rautaharju PM. Prevalence of atrial fibrillation in elderly subjects (the Cardiovascular Health Study). American Journal of Cardiology 1994;74:236-41.

\section{Fuster 2006}

Fuster V, Rydén LE, Cannom DS, Crijns HJ, Curtis AB, Ellenbogen KA, et al. ACC/AHA/ESC 2006 guidelines for the management of patients with atrial fibrillation: a report of the American College of Cardiology/American Heart Association Task Force on Practice Guidelines and the European Society of CardiologyCommittee for Practice Guidelines (Writing Committee to Revise the 2001 Guidelines for the Management of Patients With Atrial Fibrillation). Journal of the American College of Cardiology 2006;48:149-246.

\section{Go 2001}

Go AS, Hylek EM, Phillips KA, Chang Y, Henault LE, Selby JV, et al. Prevalence of diagnosed atrial fibrillation in adults: national implications for rhythm management and stroke prevention: the AnTicoagulation and Risk Factors in Atrial Fibrillation (ATRIA) Study. JAMA 2001;285:2370-5.

\section{Goroll 1995}

Goroll AH, May LA, Mulley AG. Primary care medicine. Third edition. Philadelphia: Lippincott, 1995.

\section{Gowd 2012}

Gowd BM, Thompson PD. Effect of female sex on cardiac arrhythmias. Cardiology in Review 2012;20(6):297-303.

\section{Grogan 1992}

Grogan M, Smith HC, Gersh BJ, Wood DL. Left ventricular dysfunction due to atrial fibrillation in patients initially believed to have idiopathic dilated cardiomyopathy. American Journal of Cardiology 1992;69(19):1570-3.

\section{Harris 2011}

Harris R, Sawaya GF, Moyer VA, Calonge N. Reconsidering the criteria for evaluating proposed screening programs: reflections from 4 current and former members of the U.S. Preventive Services Task Force. Epidemiologic Reviews 2011;33:20-35.

\section{Harris 2012}

Harris K, Edwards D, Mant J. How can we best detect atrial fibrillation? The Journal of the Royal College of Physicians of Edinburgh 2012;42 Suppl 18:5-22.

\section{Hart 2007}

Hart RG, Pearce LA, Aguilar MI. Meta-analysis: antithrombotic therapy to prevent stroke in patients who have nonvalvular atrial fibrillation. Annals of Internal Medicine 2007;146(12):857-67.

\section{Heeringa 2006}

Heeringa J, van de Kuip DAM, Hofman A, Kors JA, van Herpen G, Stricker BHCh, et al. Prevalence, incidence and lifetime risk of atrial fibrillation: the Rotterdam study. European Heart Journal 2006;27:949-53.

\section{Higgins 2011}

Higgins JPT, Green S (editors). Cochrane Handbook for Systematic Reviews of Interventions Version 5.1.0 [updated March 2011]. The Cochrane Collaboration, 2011. ;www.cochrane-handbook.org.

\section{Hohnloser 2007}

Hohnloser SH, Pajitnev D, Pogue J, Healey JS, Pfeffer MA, Yusuf $\mathrm{S}$, et al. Incidence of stroke in paroxysmal versus sustained atrial fibrillation in patients taking oral anticoagulation or combined antiplatelet therapy: an ACTIVE W Substudy. Journal of the American College of Cardiology 2007;50(22):2156-61.

\section{Jepson 2000}

Jepson R, Clegg A, Forbes C, Lewis R, Sowden A, Kleijnen J. The determinants of screening uptake and interventions for increasing uptake: a systematic review. Health Technology Assessment 2000;4(14):1-133.

\section{Kannel 1983}

Kannel WB, Abbott RD, Savage DD, McNamara PM. Coronary heart disease and atrial fibrillation: the Framingham Study. American Heart Journal 1983;106:389-96.

\section{Krahn 1995}

Krahn AD, Manfreda J, Tate RB, Mathewson FA, Cuddy TE. The natural history of atrial fibrillation: incidence, risk factors, and prognosis in the Manitoba Follow-Up Study. American Journal of Medicine 1995;98:476-84.

\section{Lefebvre 2011}

Lefebvre C, Manheimer E, Glanville J. Chapter 6: Searching for studies. In: Higgins JPT, Green S, editors(s). Cochrane Handbook for Systematic Reviews of Interventions Version 5.1.0 [updated March 2011]. The Cochrane Collaboration, 2011. www.cochranehandbook.org.

\section{Levy 2003}

Levy S, Camm AJ, Saksena S, Aliot E, Breithardt G, Crijns H, et al. International consensus on nomenclature and classification of atrial fibrillation; a collaborative project of the Working Group on Arrhythmias and the Working Group on Cardiac Pacing of the European Society of Cardiology and the North American Society of Pacing and Electrophysiology. Europace 2003;5:119-22.

\section{Lin 1995}

Lin HJ, Wolf PA, Benjamin EJ, Belanger AJ, D'Agostino RB. Newly diagnosed atrial fibrillation and acute stroke. The Framingham Study. Stroke 1995;26(9):1527-30.

\section{Lin 1996}

Lin HJ, Wolf PA, Kelly-Hayes M, Beiser AS, Kase CS, Benjamin EJ, et al. Stroke severity in atrial fibrillation. The Framingham Study. Stroke 1996;27:1760-4.

\section{Lip 2012}

Lip GY, Brechin CM, Lane DA. The global burden of atrial fibrillation and stroke: a systematic review of the epidemiology of atrial fibrillation in regions outside North America and Europe. Chest 2012;142(6):1489-98. 


\section{McGregor 2006}

McGregor P, Nolan A, Nolan B, O'Neill C. A comparison of GP visiting in Northern Ireland and the Republic of Ireland. ESRI Research Programme on Health Services, Health Inequalities and Health and Social Gain 2006; Working paper No. 22.

\section{NCCCC 2006}

National Collaborating Centre for Chronic Conditions. Atrial fibrillation: national clinical guideline for management in primary and secondary care. London: Royal College of Physicians, 2006.

\section{Ogilvie 2010}

Ogilvie IM, Newton N, Welner SA, Cowell W, Lip GY. Underuse of oral anticoagulants in atrial fibrillation: a systematic review. American Journal of Medicine 2010;123(7):638-45.

\section{Ott 1997}

Ott A, Breteler MM, de Bruyne MC, van Harskamp F, Grobbee DE, Hofman A. Atrial fibrillation and dementia in a populationbased study. The Rotterdam Study. Stroke 1997;28(2):316-21.

\section{Parkin 2008}

Parkin DM, Tappenden P, Olsen AH, Patnick J, Sasieni P. Predicting the impact of the screening programme for colorectal cancer in the UK. Journal of Medical Screening 2008;15(4):163-74.

\section{Peate 2004}

Peate I. Men's attitudes towards health and the implications for nursing care. British Journal of Nursing 2004;13(9):540-5.

\section{Psaty 1997}

Psaty BM, Manolio TA, Kuller LH, Kronmal RA, Cushman M, Fried LP, et al. Incidence of and risk factors for atrial fibrillation in older adults. Circulation 1997;96(7):2455-61.

\section{Savelieva 2000}

Savelieva I, Camm AC. Clinical relevance of silent atrial fibrillation: prevalence, prognosis, quality of life and management. Journal of Interventional Cardiac Electrophysiology 2000;4:369-82.

\section{Stewart 2001}

Stewart S, Maclntyre K, MacLeod MM, Bailey AE, Capewell S, McMurray JJ. Trends in hospital activity,morbidity and case fatality related to atrial fibrillation in Scotland,1986-1996. European Heart Journal 2001;22(8):693-701.

\section{Stewart 2002}

Stewart S, Hart CL, Hole DJ, McMurray JJ. A population-based study of the long-term risks associated with atrial fibrillation:

\section{CHARACTERISTICS OF STUDIES}

Characteristics of included studies [ordered by study ID] 20-year follow-up of the Renfrew/Paisley study. American Journal of Medicine 2001;113(5):359-64.

\section{Swancutt 2004}

Swancutt D, Hobbs R, Fitzmaurice D, Mant J, Murray E, Jowett S, et al. A randomised controlled trial and cost effectiveness study of systematic screening (targeted and total population screening) versus routine practice for the detection of atrial fibrillation in the over 65s: (SAFE) [ISRCTN19633732]. BMC Cardiovascular Disorders 2004;4:12.

\section{Wardle 2005}

Wardle J, Miles A, Atkin W. Gender differences in utilization of colorectal cancer screening. Journal of Medical Screening 2005;12(1):20-7.

\section{Wattigney 2003}

Wattigney WA, Mensah GA, Croft JB. Increasing trends in hospitalization for atrial fibrillation in the United States, 1985 through 1999: implications for primary prevention. Circulation 2003;108:711-6.

\section{Weller 2009}

Weller DP, Campbell C. Uptake in cancer screening programmes: a priority in cancer control. British Journal of Cancer 2009;101 Suppl 2:S55-9.

\section{Wilson Jungner 1968}

Wilson JMG, Jungner G. Principles and practice of screening for disease. Geneva, Switzerland: World Health Organization, 1968.

\section{Wolf 1983}

Wolf PA, Kannel WB, McGee DL, Meeks SL, Bharucha NE, McNamara PM. Duration of atrial fibrillation and imminence of stroke: the Framingham study. Stroke 1983;14(5):664-7.

\section{Wolf 1987}

Wolf PA, Abbott RD, Kannel WB. Atrial fibrillation: a major contributor to stroke in the elderly. The Framingham Study. Archives of Internal Medicine 1987;147(9):1561-4.

\section{Wolf 1991}

Wolf PA, Abbott RD, Kannel WB. Atrial fibrillation as an independent risk factor for stroke: the Framingham Study. Stroke 1991;22(8):983-8.

\section{Wyse 2002}

Wyse DG, Waldo AL DiMarco JP, Domanski MJ, Rosenberg Y, Schron EB, et al. A comparison of rate control and rhythm control in patients with atrial fibrillation. New England Journal of Medicine 2002;347(23):1825-33. 
Hobbs 2005 (Continued)

Methods
Multi-centre cluster-randomised controlled trial involving 50 (computerised) primary care centres across the West Midlands, UK, over a 12-month period. Randomisation was stratified by levels of deprivation (Townsend quartiles) and practice size. A subsidiary trial embedded in the intervention arm compared 2 different screening strategies. The overall time period was from October 2001 to February 2003

Participants

Male and female patients over 65 years of age attending general practices in the UK Age range was 65 to 98 years; average age was 73.5 years

A random sample of 10,000 participants from the intervention group were allocated randomly to systematic or opportunistic screening. Randomisation was stratified according to whether or not atrial fibrillation (AF) had been previously diagnosed to have an equal prevalence of known AF on both arms A random sample of 5000 was selected from the control population. After sampling, lists were returned to practices to remove those who had died, moved or were terminally ill. These patients were replaced from a back-up list, which had been randomised at the same time as the initial list

Final number of participants in control arm $=4963$ from 25 general practices

Final number of participants in intervention arms $=4933$ for opportunistic screening and 4933 for systematic screening from 25 general practices

Baseline AF prevalence in the control population was higher than in the intervention populations (7.9\% vs $6.9 \%)$

Interventions

Training:

- Staff at primary care centres in the intervention arms were given training on the importance of AF detection and available treatment options, and were encouraged to consider opportunistic screening of patients. Staff at control centres were given no training. Practice nurses received ECG training before starting ECG clinics

Systematic screening:

- All participants in the systematic screening arm were sent an invitation to attend a screening clinic along with an information sheet. Non-responders were sent a reminder

Opportunistic screening:

- Participants in the opportunistic screening arm had their records flagged to encourage staff to undertake pulse recordings during routine consultation. Those who had an irregular pulse were given an information sheet and were invited to attend a screening clinic

Screening clinics:

- Screening clinics were run by practice nurses, who took patient histories, checked radial pulse rate and whether it was regular or irregular and recorded a 12-lead electrocardiogram (ECG). Participants were then asked to complete a questionnaire on the acceptability of the intervention. All 12-lead ECGs were sent to 2 cardiologists for reporting. If disagreement over the diagnosis arose, a third cardiologist decided. Patients were informed of the results within 2 weeks

Primary outcomes:
- New cases of atrial fibrillation detected within the 12-month study period
- Incremental cost per case detected
Secondary outcomes:
- Cost-effectiveness of screening in the UK
- Community prevalence and incidence of AF
- Acceptability of AF screening and patient uptake


Hobbs 2005 (Continued)

Funding This research was funded by the NHS research and development health technology assessment programme (No. 96/22/11)

Notes

Intention-to-treat analysis was performed, and patients who already had a diagnosis of AF were excluded from the calculation of newly detected cases

\section{Risk of bias}

\section{Bias \\ Authors' judgement Support for judgement}

Random sequence genera- Low risk tion (selection bias)

- Probably done for control and intervention groups: "After stratification for practice size and deprivation (based on Townsend score), we used MINITAB to select randomly two equal size groups from those practices within a particular stratum. We used a simulated value from a Bernoulli distribution, comprising two values equally likely to occur, to determine which group became the intervention arm (the other being the control arm)"

- Also probably done for embedded trial within the intervention arm: "We used SPSS to allocate patients randomly from this list to either systematic or opportunistic screening to create two equal size groups of patients within each stratum so that each strategy (systematic or opportunistic screening) had an equal chance of detecting known, unknown, and suspected atrial fibrillation $(n=4933)$. Which group then became the systematic arm (the other being opportunistic) was again decided by using a simulated value from a Bernoulli distribution, comprising two values equally likely to occur"

Allocation concealment Unclear risk

(selection bias)

Study authors state "there was no deliberate concealment of allocation to the trial arms...the trial statistician determined allocation, which was implemented by the trial coordinator". However, clusters (general practitioner (GP) practices) were identified and recruited before randomisation was conducted, so allocation was concealed from the people providing permission for the cluster to be included in the trial. Similarly, patients in the intervention arm were identified and randomly allocated to 2 groups before it was known to anyone involved in the trial which group would be allocated to which treatment (opportunistic or systematic), because this was decided at the end of the randomisation process on the basis of a simulated value from a Bernoulli distribution, comprising 2 values equally likely to occur. However, as no deliberate attempt was made to conceal allocation, it is unclear to what extent a risk of selection bias might have arisen from awareness of practices in the intervention arm that they were in the intervention arm and not the control arm before participants were recruited

Blinding of participants and personnel (performance bias)

All outcomes
High risk

It was not possible to blind participants, who were notified by letter that they were being offered the opportunity to participate in an atrial fibrillation (AF) screening clinic or were encouraged to have their pulse recorded during routine consultation. Neither were primary care physicians and healthcare staff blinded because the intervention arm received training during which they were informed of the importance of detecting AF and receiving treatment. Practice nurses at screening clinics who took patients' medical history, pulse and electrocardiogram (ECG) probably were not blinded to whether the patient came from the systematic or opportunistic arm. Blinding is not feasible in a situation where well-informed patients who need to decide whether they want to avail themselves of screening are a key component of the systematic screening intervention. However, because a study that cannot be blinded is not equal to a blinded study, it is classified as high risk. Screening clinics were used to test patients from each group according to the same protocol and with the aid of a 12-lead ECG machine (Biolog) 
Hobbs 2005 (Continued)

Blinding of outcome as- Low risk Blinding was performed when possible; cardiologists who interpreted the 12sessment (detection bias) lead ECG reading to make a diagnosis of AF were blinded as to the allocation of All outcomes the participant from whom the ECG was taken

Incomplete outcome data Low risk (attrition bias)

All outcomes

After random sampling to identify participants from the cluster-randomised primary care centres, general practices were contacted to exclude people who had died, had moved away or were terminally ill. These exclusions were randomly filled from a reserve list of $10 \%$ of practice patients, which was randomised at the same time as the original list. Immediately before sending screening invitations or flagging notes, investigators again contacted general practices to exclude people who had since died, moved or were terminally ill, and these exclusions were not replaced; the numbers in each arm were reported. The primary outcome was calculated by taking the original figure and using an intention-to-treat (ITT) approach. Patients within each group who had already received a diagnosis of AF were excluded from the calculation of the primary outcome (new cases detected). This necessitated a review of patient records to identify those with a pre-existing diagnosis. Records for some people in each group were missing and were reported for each group individually. Both participants with AF and those with missing notes were excluded from the calculation of the rate of new cases detected

Selective reporting (re- Low risk All outcomes specified in the trial protocol were reported
porting bias)

Other bias

Unclear risk

\begin{abstract}
The potential for recruitment bias and contamination is noted in the study. Recruitment bias could have been introduced at the stage where general practitioners were asked to exclude unsuitable patients from opportunistic and systematic screening arms within the intervention group. Advice was given to exclude those from both groups who had died, had moved away or were terminally ill. People excluded at this stage were replaced from a back-up list of patients that had been randomised at the same time as the groups. No data are provided about how many from each group were replaced at this stage, nor is the breakdown of reasons for their exclusion given. Immediately before the intervention was provided, GPs again were asked to exclude any patients who had died, had moved away or were terminally ill from both groups. Data concerning exclusions at this stage are reported, and a considerable difference in numbers excluded was noted between the 2 arms; 500 were excluded from the systematic screening arm (10\% of total) and 195 from the opportunistic arm (4\% of total). However, individual reasons for exclusion from the systematic screening arm were reported, and only a small minority of these (9 people, $0.2 \%$ of total) were deemed unsuitable, as opposed to having died or moved away (491 people, $9.9 \%$ of total). An ITT analysis included participants removed from the intervention group at this stage in the calculation of the primary outcome
\end{abstract}

\title{
Characteristics of excluded studies [ordered by study ID]
}

\begin{tabular}{|c|c|}
\hline Study & Reason for exclusion \\
\hline ACTRN12612000406808 & $\begin{array}{l}\text { Ineligible study design - no control group. This is an ongoing non-randomised registered trial in } \\
\text { which community pharmacists will screen members of the general public for atrial fibrillation using } \\
\text { a combination of a manual pulse check and a handheld single-lead ECG (using the AliveCor Heart } \\
\text { Monitor for iPhone). This will be a once-off screening of approximately } 5 \text { to } 10 \text { minutes in duration. } \\
\text { After screening, the pharmacist will contact the participant's GP via letter, stating the provisional } \\
\text { diagnosis. A cardiologist will review all single-lead ECG recordings to ensure that the pharmacist's } \\
\text { interpretation is correct. The GP will be further contacted by the research team if the diagnosis is }\end{array}$ \\
\hline
\end{tabular}




\begin{tabular}{ll}
\hline Study & Reason for exclusion \\
\hline $\begin{array}{l}\text { other than that reported by the pharmacist. The screening trial will be conducted over a 6-month } \\
\text { period }\end{array}$ \\
\hline Baxter 1998 & $\begin{array}{l}\text { Ineligible study design - this was a pilot study of self screening for AF in an older population (age } \\
\text { range 55-75 years). No controls were used and irregular pulse readings were not confirmed by ECG. } \\
\text { Communication with the corresponding author indicated that the study had not been continued } \\
\text { after the time of this publication }\end{array}$ \\
\hline
\end{tabular}

Bury 2015

Ineligible study design - this was a cross-sectional study conducted to examine the use of 3-lead ECG as an AF screening tool for individuals over 70 years of age in general practice in Ireland. A 12lead ECG was only performed when a 3-lead ECG did not produce a useable trace. An uptake rate of $64 \%$ was reported (639/1003), and 12 of the 566 participants who completed screening were newly diagnosed with $\mathrm{AF}(2.1 \%)$

Claes 2012

Ineligible study design - no control group. This report describes a study in which "patients over 40 years were invited through different channels (TV, radio, journals, web site, posters, leaflets) for a free screening in 69 hospitals allocated over Belgium during one week. After filling in a question on their personal history of AF, they had to fill in a questionnaire about their CHADS2-score. Afterwards a one channel ECG was taken using a versatile Heart Scan Device (Omron HCG-801-E) by a trained nurse or a physician. If the ECG was positive for AF the patient was referred to their physician for follow-up." No control group receiving routine care was included to examine the effect of the intervention compared with no screening. 10,758 people over 40 years of age participated, resulting in 167 new diagnoses of AF. When calculated on the basis of those who responded to the media campaign, the detection rate for new cases of AF is approximately $1.56 \%$. It is not possible to calculate the rate of detection based on the total number of people who received an invitation

DeRuijter 2008

Ineligible study design - this was a prospective cohort study conducted to evaluate whether routinely performed ECGs in older people from the general population have added value for cardiovascular risk management beyond the information already available from medical records

Ineligible study design - no controls. In this study, "500 subjects were drawn by two-stage random sampling from 5,002 subjects aged 70 years and over living at home. Subjects were screened for atrial fibrillation and left ventricular systolic dysfunction using electrocardiography and echocardiography." This was a prevalence study with no data on the effect of screening compared with routine care plained symptoms suggestive of arrhythmia

Johnson 2010

Ineligible study design - no controls. This conference abstract describes a study that employed a strategy of random screening in a public venue (an inner city public market) to determine stroke risk. However, no controls were used and results were not compared with multiple time points preand post-intervention. No diagnoses of AF were made

Maeda 2004

Ineligible study design - this was an economic evaluation that modelled clinical outcomes and costs associated with a screening programme in Japan

Marek 2011 Ineligible study design - this was a retrospective cohort study of large-scale electrocardiographic screening of young adults

Morgan 2002

Ineligible study design - no controls. This was a randomised trial comparing 2 different screening strategies. Participants were randomised to nurse-led screening or to prompted opportunistic case finding. Irregular pulses found during opportunistic screening did not need to be confirmed by ECG. The study was carried out over a 6 -month period. Uptake in the systematic screening arm was $73 \%$, compared with $29 \%$ (for pulse palpation alone) in the opportunistic arm. The detection rate of new cases of $\mathrm{AF}$ in the systematic arm was $0.8 \%$, compared with $0.4 \%$ in the opportunistic arm 


\begin{tabular}{ll}
\hline Study & Reason for exclusion \\
\hline Munschauer 1999 & $\begin{array}{l}\text { Ineligible study design - this study was designed to determine whether individuals taken from the } \\
\text { general community could be taught to find and classify the pulse of another as very irregular, im- } \\
\text { plying AF, or regular, implying normal sinus rhythm (NSR). No data on the effectiveness of a screen- } \\
\text { ing programme compared with routine practice were reported }\end{array}$
\end{tabular}

Somerville 2000

Ineligible study design - this study compared different methods of identifying cases in general practice using patients over 65 recruited from a general practice. $56 \%$ of invitees accepted an invitation for testing (86/154), but no data on the rate of detection of new cases were reported. The study was not designed to investigate the effect of screening compared with routine practice

Sudlow 1998

Ineligible study design - no controls. This study compares 3 methods of diagnosing AF in a sample of 1235 individuals over 65 years of age invited from 9 general practices in the UK. Methods of screening used were (1) checking for a digoxin prescription, (2) performing pulse palpation and (3) obtaining a limb lead ECG. Response rate was 74\% (916/1235). No data on rate of new diagnoses were reported

Virtanen 2014

This study examined the feasibility of training people over 75 years of age to palpate their own pulse to help detect AF. No control group was included. $68 \%$ of participants (139/205) regularly palpated their own pulse during the 1-month follow up period and $2.9 \%$ (4/139) were newly diagnosed with AF.

Wheeldon 1998

Ineligible study design - all patients over 65 years of age from a single primary care practice with 4 GPs were invited to attend for a 12 -lead ECG to detect AF. An uptake rate of $85 \%$ was achieved (1207/1422). The overall detection rate of new cases of AF was approximately $0.4 \%$

Wright 2007 Ineligible study design - no controls. This study randomised primary care centres to implementing AF or TIA guidelines. The type of AF testing associated with AF guidelines was unclear, but effects on the rate of diagnosis of new cases of AF were reported. However, no control arm receiving routine care was included

\section{Characteristics of ongoing studies [ordered by study ID]}

NCT01291953

Study name

Methods

Participants

women over 65 years of age who are attending a primary care centre for any reason. $\mathrm{Pa}$ tients with a prior diagnosis of atrial fibrillation (AF) will be excluded. Anticipated enrolment of 12,870 participants
Effectiveness of Early Detection of Atrial Fibrillation (FAMDAP)

Multi-centre cluster-randomised controlled trial. Primary care centre professionals will be randomised to the intervention group or a control group involving routine practice

\begin{tabular}{ll}
\hline Interventions & Opportunistic screening of people aged 65 years or older presenting for primary care services. Op- \\
portunistic screening will involve pulse taking and requesting an electrocardiogram (ECG) if an ir- \\
regular pulse is found
\end{tabular}

$\begin{array}{ll}\text { Outcomes } & \begin{array}{l}\text { Primary outcome is the number of new diagnoses of AF per opportunistic screening versus routine } \\ \text { practice }\end{array}\end{array}$

\begin{tabular}{ll}
\hline Starting date & January 2011 \\
\hline Contact information & $\begin{array}{l}\text { Principal Investigator: Luis Angel Pérula de Torres, Andalusian Health Service, langel.perula.ss- } \\
\text { pa@juntadeandalucia.es }\end{array}$ \\
\hline
\end{tabular}


NCT01291953 (Continued)

Notes
Trial protocol published (BMC Fam Pract.2012;13:106.). Study completion date June 2015. Publication awaited.

ClinicalTrials.gov identifier: NCT01291953

\section{NCT01593553}

Study name

Methods

Participants

Participants

Interventions

Systematic ECG Screening for Atrial Fibrillation Among 75 Year Old Subjects in the Region of Stockholm and Halland, Sweden

\begin{tabular}{ll}
\hline Outcomes & Reduced incidence of stroke among 75-year-old participants \\
\hline Starting date & March 2012 \\
\hline Contact information & Anna Hollander, RN LicMedSci, +46-8-51778214, anna.hollander@karolinska.se \\
\hline Notes & Trial ongoing, estimated completion March 2019 \\
& ClinicalTrials.gov identifier: NCT01593553 \\
\hline
\end{tabular}

\section{DATA AND ANALYSES}

\section{Comparison 1. Detection of new cases of atrial fibrillation versus routine practice}

\begin{tabular}{|c|c|c|c|c|}
\hline Outcome or subgroup title & No. of studies & $\begin{array}{l}\text { No. of partici- } \\
\text { pants }\end{array}$ & Statistical method & Effect size \\
\hline $\begin{array}{l}1.1 \text { Systematic screening vs } \\
\text { routine practice }\end{array}$ & 1 & 9075 & Odds Ratio (M-H, Fixed, 95\% Cl) & $1.57[1.08,2.26]$ \\
\hline $\begin{array}{l}1.2 \text { Opportunistic screening } \\
\text { vs routine practice }\end{array}$ & 1 & 9088 & Odds Ratio (M-H, Fixed, 95\% Cl) & $1.58[1.10,2.29]$ \\
\hline $\begin{array}{l}1.3 \text { Gender subgroups (sys- } \\
\text { tematic) }\end{array}$ & 1 & 9075 & Odds Ratio (M-H, Fixed, 95\% Cl) & $1.56[1.08,2.26]$ \\
\hline 1.3.1 Men & 1 & 3838 & Odds Ratio (M-H, Fixed, 95\% Cl) & $2.68[1.51,4.76]$ \\
\hline 1.3.2 Women & 1 & 5237 & Odds Ratio (M-H, Fixed, 95\% Cl) & $0.98[0.59,1.62]$ \\
\hline $\begin{array}{l}\text { 1.4 Age subgroups (system- } \\
\text { atic) }\end{array}$ & 1 & 9075 & Odds Ratio (M-H, Fixed, 95\% Cl) & $1.58[1.09,2.29]$ \\
\hline
\end{tabular}




\begin{tabular}{|c|c|c|c|c|}
\hline Outcome or subgroup title & No. of studies & $\begin{array}{l}\text { No. of partici- } \\
\text { pants }\end{array}$ & Statistical method & Effect size \\
\hline 1.4.1 Aged $65-74$ years & 1 & 5034 & Odds Ratio (M-H, Fixed, 95\% Cl) & $1.62[0.90,2.91]$ \\
\hline 1.4.2 Aged $>74$ years & 1 & 4041 & Odds Ratio (M-H, Fixed, 95\% Cl) & $1.56[0.97,2.50]$ \\
\hline $\begin{array}{l}1.5 \text { Gender subgroups (op- } \\
\text { portunistic) }\end{array}$ & 1 & 9088 & Odds Ratio (M-H, Fixed, 95\% Cl) & $1.58[1.10,2.29]$ \\
\hline 1.5.1 Men & 1 & 3821 & Odds Ratio (M-H, Fixed, 95\% Cl) & $2.33[1.29,4.19]$ \\
\hline 1.5.2 Women & 1 & 5267 & Odds Ratio (M-H, Fixed, 95\% CI) & $1.20[0.74,1.93]$ \\
\hline $\begin{array}{l}1.6 \text { Age subgroups (oppor- } \\
\text { tunistic) }\end{array}$ & 1 & 9088 & Odds Ratio (M-H, Fixed, 95\% Cl) & $1.61[1.12,2.33]$ \\
\hline 1.6.1 Aged $65-74$ years & 1 & 5100 & Odds Ratio (M-H, Fixed, 95\% Cl) & $1.63[0.91,2.92]$ \\
\hline 1.6.2 Aged $>74$ years & 1 & 3988 & Odds Ratio (M-H, Fixed, 95\% Cl) & $1.60[1.00,2.57]$ \\
\hline
\end{tabular}

Analysis 1.1. Comparison 1: Detection of new cases of atrial fibrillation versus routine practice, Outcome 1: Systematic screening vs routine practice

\begin{tabular}{|c|c|c|c|c|c|c|c|c|}
\hline \multirow[b]{2}{*}{ Study or Subgroup } & \multicolumn{2}{|c|}{ Systematic Screening } & \multicolumn{2}{|c|}{ Routine Practice } & \multirow[b]{2}{*}{ Weight } & Odds Ratio & \multirow{2}{*}{\multicolumn{2}{|c|}{$\begin{array}{c}\text { Odds Ratio } \\
\text { M-H, Fixed, } 95 \% \text { CI }\end{array}$}} \\
\hline & Events & Total & Events & Total & & M-H, Fixed, 95\% CI & & \\
\hline Hobbs 2005 & 74 & 4562 & 47 & 4513 & $100.0 \%$ & $1.57[1.08,2.26]$ & & \\
\hline Total $(95 \%$ CI) & & 4562 & & 4513 & $100.0 \%$ & $1.57[1.08,2.26]$ & & \\
\hline Total events: & 74 & & 47 & & & & & \\
\hline \multicolumn{3}{|c|}{ Heterogeneity: Not applicable } & & & & 0.01 & 0.1 & $10 \quad 100$ \\
\hline Test for overall effect & $2.39(\mathrm{P}=0$. & & & & & Favours Rout & Practice & Favours Screening \\
\hline
\end{tabular}

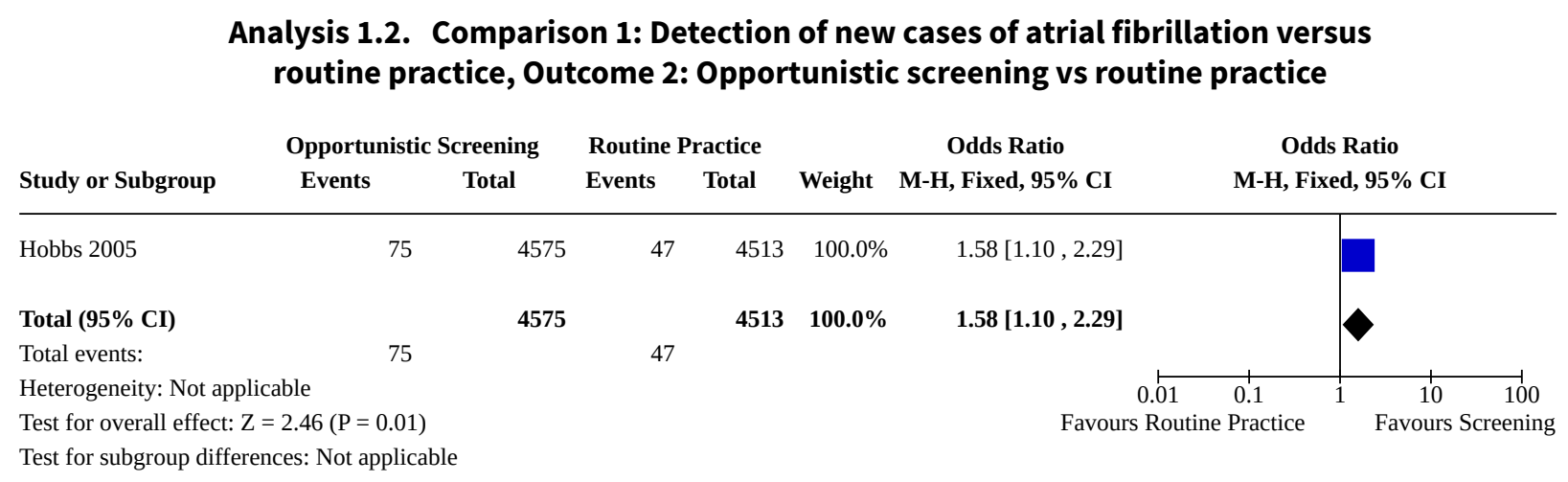


Analysis 1.3. Comparison 1: Detection of new cases of atrial fibrillation versus routine practice, Outcome 3: Gender subgroups (systematic)

\begin{tabular}{|c|c|c|c|c|c|c|c|}
\hline & Systema & reening & Routin & ractice & & Odds Ratio & Odds Ratio \\
\hline Study or Subgroup & Events & Total & Events & Total & Weight & M-H, Fixed, 95\% CI & M-H, Fixed, 95\% CI \\
\hline
\end{tabular}

\begin{tabular}{lcccccc}
\hline $\mathbf{1 . 3 . 1}$ Men & & & & & & \\
Hobbs 2005 & 44 & 1958 & 16 & 1880 & $34.4 \%$ & $2.68[1.51,4.76]$ \\
Subtotal (95\% CI) & & $\mathbf{1 9 5 8}$ & & $\mathbf{1 8 8 0}$ & $\mathbf{3 4 . 4 \%}$ & $\mathbf{2 . 6 8}[\mathbf{1 . 5 1 , \mathbf { 4 }} \mathbf{4 6}]$ \\
Total events: & 44 & & 16 & & &
\end{tabular}

Total events:

Heterogeneity: Not applicable

Test for overall effect: $\mathrm{Z}=3.35(\mathrm{P}=0.0008)$

\subsubsection{Women}

Hobbs 2005

Subtotal (95\% CI)

$30 \quad 2604$

31

$2633 \quad 65.6 \%$

$0.98[0.59,1.62]$

Total events:

30

2604

31

$0.98[0.59,1.62]$

Heterogeneity: Not applicable

Test for overall effect: $\mathrm{Z}=0.09(\mathrm{P}=0.93)$

Total $(95 \%$ CI $)$

4562

$4513 \quad 100.0 \%$

$1.56[1.08,2.26]$

Total events:

74

47

Heterogeneity: $\mathrm{Chi}^{2}=6.67, \mathrm{df}=1(\mathrm{P}=0.010) ; \mathrm{I}^{2}=85 \%$

Test for overall effect: $\mathrm{Z}=2.37(\mathrm{P}=0.02)$

Test for subgroup differences: $\mathrm{Chi}^{2}=6.64, \mathrm{df}=1(\mathrm{P}=0.010), \mathrm{I}^{2}=84.9 \%$

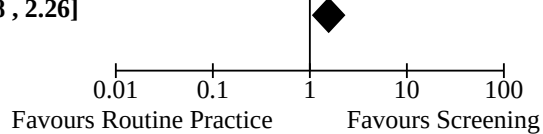
Analysis 1.4. Comparison 1: Detection of new cases of atrial fibrillation
versus routine practice, Outcome 4: Age subgroups (systematic)

\begin{tabular}{|c|c|c|c|c|}
\hline & Systematic Screening & Routine Practice & Odds Ratio & Odds Ratio \\
\hline Study or Subgroup & Events $\quad$ Total & Events Total & M-H, Fixed, 95\% CI & M-H, Fixed, 95\% CI \\
\hline
\end{tabular}

\subsubsection{Aged 65-74 years}

Hobbs 2005

$30 \quad 2562$

18

$2472 \quad 39.2 \%$

$1.62[0.90,2.91]$

Subtotal (95\% CI)

2562

$2472 \quad 39.2 \%$

$1.62[0.90,2.91]$

Heterogeneity: Not applicable

Test for overall effect: $\mathrm{Z}=1.60(\mathrm{P}=0.11)$

1.4.2 Aged $>74$ years

Hobbs 2005

30

18

Subtotal (95\% CI)

Total events:

$44-2000$

29

$2041 \quad 60.8 \%$

$1.56[0.97,2.50]$

2000

$204160.8 \%$

$1.56[0.97,2.50]$

Heterogeneity: Not applicable

Test for overall effect: $\mathrm{Z}=1.84(\mathrm{P}=0.07)$

Total (95\% CI)

4562

$4513 \quad 100.0 \%$

$1.58[1.09,2.29]$

Total events:

74

47

Heterogeneity: Chi $^{2}=0.01, \mathrm{df}=1(\mathrm{P}=0.93) ; \mathrm{I}^{2}=0 \%$

Test for overall effect: $\mathrm{Z}=2.44(\mathrm{P}=0.01)$

Test for subgroup differences: $\mathrm{Chi}^{2}=0.01, \mathrm{df}=1(\mathrm{P}=0.93), \mathrm{I}^{2}=0 \%$

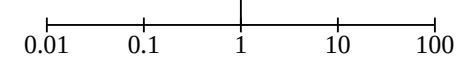

Favours Routine Practice 
Analysis 1.5. Comparison 1: Detection of new cases of atrial fibrillation versus routine practice, Outcome 5: Gender subgroups (opportunistic)

\begin{tabular}{ccccccc} 
& \multicolumn{2}{c}{ Opportunistic } & \multicolumn{2}{c}{ Routine Practice } & Odds Ratio & Odds Ratio \\
Study or Subgroup & Events $\quad$ Total & Events & Total & Weight & M-H, Fixed, 95\% CI & M-H, Fixed, 95\% CI
\end{tabular}

\begin{tabular}{lcccccc}
\hline $\mathbf{1 . 5 . 1}$ Men & & & & & & \\
Hobbs 2005 & 38 & 1941 & 16 & 1880 & $34.3 \%$ & $2.33[1.29,4.19]$ \\
Subtotal (95\% CI) & & $\mathbf{1 9 4 1}$ & & $\mathbf{1 8 8 0}$ & $\mathbf{3 4 . 3 \%}$ & $\mathbf{2 . 3 3}[\mathbf{1 . 2 9}, \mathbf{4 . 1 9}]$ \\
Total events: & 38 & & 16 & & &
\end{tabular}

Heterogeneity: Not applicable

Test for overall effect: $\mathrm{Z}=2.82(\mathrm{P}=0.005)$

\subsubsection{Women}

Hobbs 2005

Subtotal (95\% CI)

$37 \quad 2634$

31

2633

$65.7 \%$

$1.20[0.74,1.93]$

Total events:

37

2633

$65.7 \%$

$1.20[0.74,1.93]$

Heterogeneity: Not applicable

Test for overall effect: $\mathrm{Z}=0.73(\mathrm{P}=0.47)$

Total (95\% CI)

Total events:

4575

Heterogeneity: $\mathrm{Chi}^{2}=2.96, \mathrm{df}=1(\mathrm{P}=0.09) ; \mathrm{I}^{2}=66 \%$

Test for overall effect: $\mathrm{Z}=2.45(\mathrm{P}=0.01)$

Test for subgroup differences: $\mathrm{Chi}^{2}=2.95, \mathrm{df}=1(\mathrm{P}=0.09), \mathrm{I}^{2}=66.1 \%$

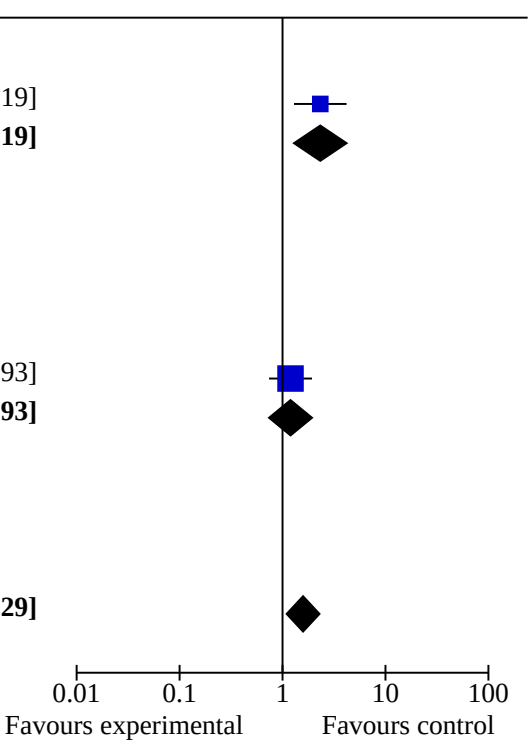

\section{Analysis 1.6. Comparison 1: Detection of new cases of atrial fibrillation versus routine practice, Outcome 6: Age subgroups (opportunistic)}

\begin{tabular}{|c|c|c|c|c|c|c|}
\hline & Opportunistic & Routin & ractice & & Odds Ratio & Odds Ratio \\
\hline Study or Subgroup & Events & Events & Total & Weight & & M-H, Fixed, 95\% CI \\
\hline
\end{tabular}

\begin{tabular}{lcccccc}
\hline 1.6.1 Aged 65-74 years & & & & & & \\
Hobbs 2005 & 31 & 2628 & 18 & 2472 & $39.8 \%$ & $1.63[0.91,2.92]$ \\
Subtotal (95\% CI) & & $\mathbf{2 6 2 8}$ & & $\mathbf{2 4 7 2}$ & $\mathbf{3 9 . 8 \%}$ & $\mathbf{1 . 6 3}[\mathbf{0 . 9 1 , 2 . 9 2 ]}$ \\
Total events: & 31 & & 18 & & &
\end{tabular}

Heterogeneity: Not applicable

Test for overall effect: $\mathrm{Z}=1.64(\mathrm{P}=0.10)$

1.6.2 Aged $>74$ years

Hobbs 2005

$44 \quad 1947$

29

$2041 \quad 60.2 \%$

$1.60[1.00,2.57]$

Subtotal (95\% CI)

1947

$204160.2 \%$

$1.60[1.00,2.57]$

Total events:

44

29

Heterogeneity: Not applicable

Test for overall effect: $\mathrm{Z}=1.96(\mathrm{P}=0.05)$

Total (95\% CI)

4575

$4513 \quad 100.0 \%$

$1.61[1.12,2.33]$

Total events:

$75 \quad 47$

Heterogeneity: $\mathrm{Chi}^{2}=0.00, \mathrm{df}=1(\mathrm{P}=0.97) ; \mathrm{I}^{2}=0 \%$

Test for overall effect: $\mathrm{Z}=2.55(\mathrm{P}=0.01)$

Test for subgroup differences: $\mathrm{Chi}^{2}=0.00, \mathrm{df}=1(\mathrm{P}=0.97), \mathrm{I}^{2}=0 \%$ 
Comparison 2. Detection of new cases of atrial fibrillation versus other screening

\begin{tabular}{lllll}
\hline $\begin{array}{l}\text { Outcome or subgroup ti- } \\
\text { tle }\end{array}$ & No. of studies & $\begin{array}{l}\text { No. of partici- } \\
\text { pants }\end{array}$ & Statistical method & Effect size \\
\hline $\begin{array}{l}\text { 2.1 Systematic vs oppor- } \\
\text { tunistic screening }\end{array}$ & 1 & 9137 & Odds Ratio (M-H, Fixed, 95\% Cl) & $0.99[0.72,1.37]$ \\
\hline 2.2 Gender subgroups & 1 & 9137 & Odds Ratio (M-H, Fixed, 95\% Cl) & $0.99[0.71,1.36]$ \\
\hline 2.2.1 Men & 1 & 3899 & Odds Ratio (M-H, Fixed, 95\% Cl) & $1.15[0.74,1.79]$ \\
\hline 2.2.2 Women & 1 & 5238 & Odds Ratio (M-H, Fixed, 95\% Cl) & $0.82[0.50,1.33]$ \\
\hline 2.3 Age subgroups & 1 & 9137 & Odds Ratio (M-H, Fixed, 95\% Cl) & $0.98[0.71,1.36]$ \\
\hline 2.3.1 Aged 65-74 years & 1 & 5190 & Odds Ratio (M-H, Fixed, 95\% Cl) & $0.99[0.60,1.64]$ \\
\hline 2.3.2 Aged >74 years & 1 & 3947 & Odds Ratio (M-H, Fixed, 95\% Cl) & $0.97[0.64,1.48]$ \\
\hline
\end{tabular}

Analysis 2.1. Comparison 2: Detection of new cases of atrial fibrillation versus other screening, Outcome 1: Systematic vs opportunistic screening

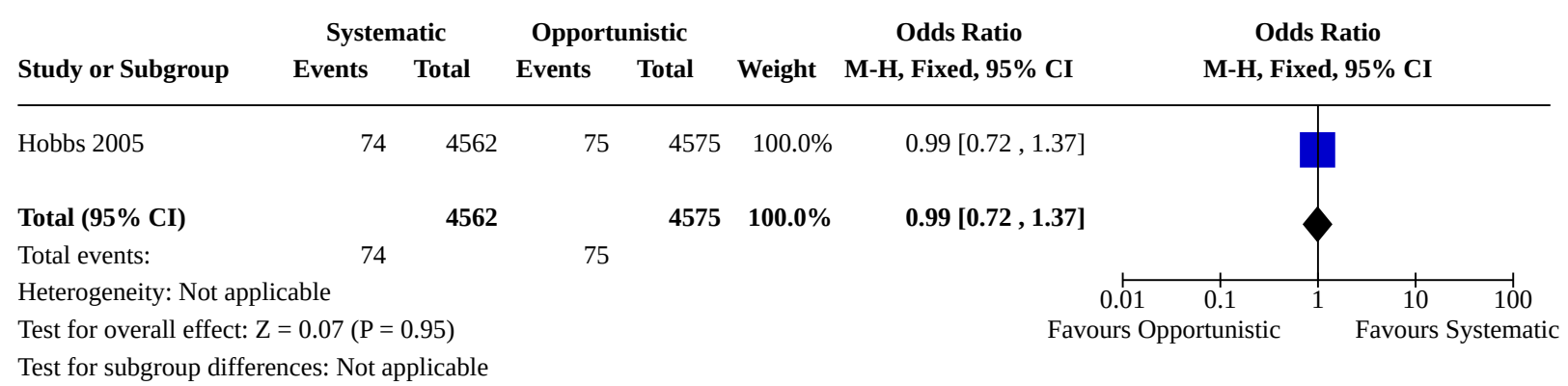


Analysis 2.2. Comparison 2: Detection of new cases of atrial fibrillation versus other screening, Outcome 2: Gender subgroups

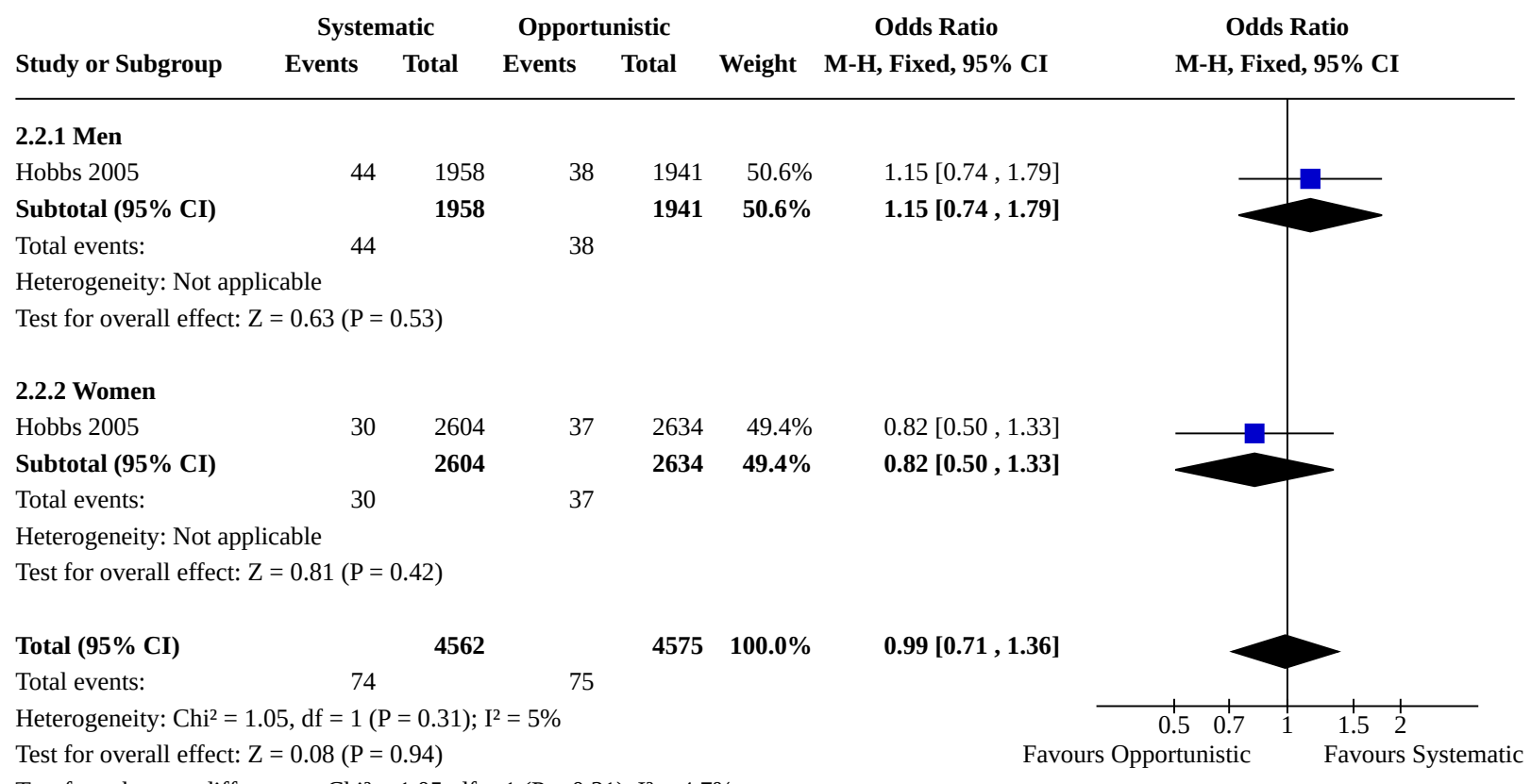

\section{Analysis 2.3. Comparison 2: Detection of new cases of atrial fibrillation versus other screening, Outcome 3: Age subgroups}

\begin{tabular}{cccccccc} 
& \multicolumn{2}{c}{ Systematic } & \multicolumn{2}{c}{ Opportunistic } & \multicolumn{2}{c}{ Odds Ratio } & Odds Ratio \\
Study or Subgroup & Events & Total & Events & Total & Weight & M-H, Fixed, 95\% CI & M-H, Fixed, 95\% CI
\end{tabular}

\begin{tabular}{lcccccc}
\hline $\begin{array}{l}\text { 2.3.1 Aged 65-74 years } \\
\text { Hobbs 2005 }\end{array}$ & 30 & 2562 & 31 & 2628 & $41.0 \%$ & $0.99[0.60,1.64]$ \\
Subtotal (95\% CI) & & $\mathbf{2 5 6 2}$ & & $\mathbf{2 6 2 8}$ & $\mathbf{4 1 . 0 \%}$ & $\mathbf{0 . 9 9}[\mathbf{0 . 6 0 , \mathbf { 1 . 6 4 } ]}$ \\
Total events: & 30 & & 31 & & &
\end{tabular}

Heterogeneity: Not applicable

Test for overall effect: $\mathrm{Z}=0.03(\mathrm{P}=0.98)$

\subsubsection{Aged $>74$ years}

Hobbs 2005

Subtotal (95\% CI)

Heterogeneity: Not applicable

Test for overall effect: $\mathrm{Z}=0.13(\mathrm{P}=0.90)$

$\begin{array}{llllll}\text { Total (95\% CI) } & 4562 & 4575 & 100.0 \% & 0.98[0.71,1.36]\end{array}$

Total events: $\quad 74 \quad 75$

Test for overall effect: $\mathrm{Z}=0.12(\mathrm{P}=0.91)$

Test for subgroup differences: $\mathrm{Chi}^{2}=0.00, \mathrm{df}=1(\mathrm{P}=0.95), \mathrm{I}^{2}=0 \%$

\section{ADDITIONAL TABLES}


Table 1. Number of new cases of atrial fibrillation detected through screening versus routine practice

\begin{tabular}{llllll}
\hline & Gender & & Age group & Total \\
\hline & Men & Women & $\mathbf{6 5 - 7 4}$ & $\mathbf{7 5 +}$ & $74 / 4562$ \\
\hline Systematic screening & $44 / 1958$ & $30 / 2604$ & $30 / 2562$ & $44 / 2000$ & $75 / 4575$ \\
\hline Opportunistic screening & $38 / 1941$ & $37 / 2634$ & $31 / 2628$ & $44 / 1947$ & $47 / 4513$ \\
\hline Routine practice & $16 / 1880$ & $31 / 2633$ & $18 / 2472$ & $29 / 2041$ & \\
\hline
\end{tabular}

Data taken from Hobbs 2005 (reported in Fitzmaurice 2007)

Table 2. Uptake of screening

\begin{tabular}{lll}
\hline Group & Systematic screening & Opportunistic screening \\
\hline All & $53 \%$ & $46 \%$ \\
\hline Men & $57 \%$ & $49 \%$ \\
\hline Women & $50 \%$ & $41 \%$ \\
\hline Aged 65-74 & $61 \%$ & $49 \%$ \\
\hline Aged $75+$ & $43 \%$ & $42 \%$ \\
\hline
\end{tabular}

Rates of uptake of screening based on data reported in Hobbs 2005. Rate of uptake of opportunistic screening is based on those who consented to have their pulse taken AND undergo an electrocardiogram (ECG) if an irregular pulse was found 


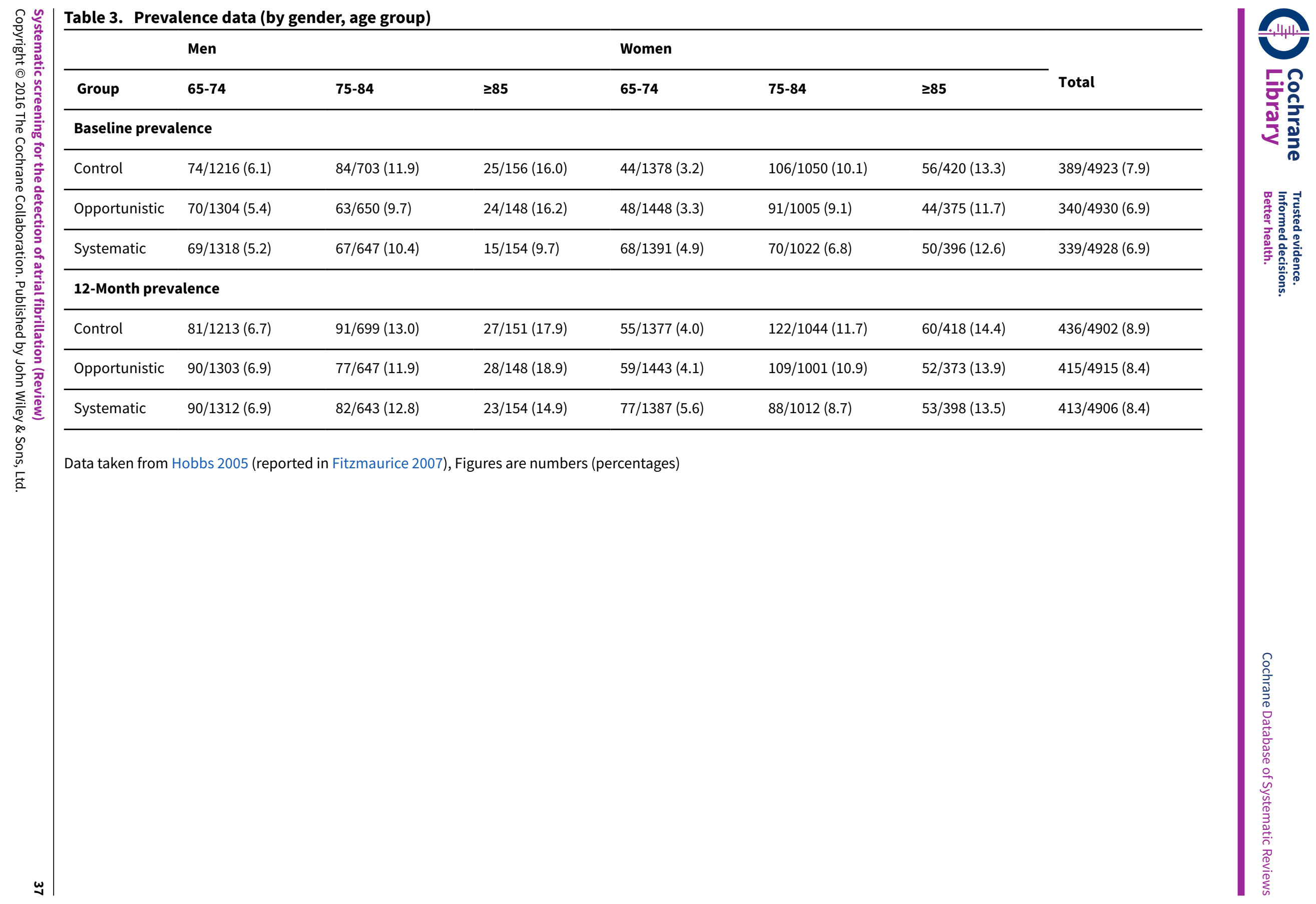




\section{APPEN DICES}

\section{Appendix 1. Search strategies - RCT \\ CENTRAL}

\#1 MeSH descriptor Mass Screening, this term only

$\# 2$ (screen $\left.{ }^{\star}\right)$

\#3 MeSH descriptor Diagnosis, this term only

\#4 MeSH descriptor Diagnostic Techniques and Procedures, this term only

\#5 diagnos*

\#6 (identif*)

\#7 test*

\#8 (prevalence)

\#9 (incidence*)

\#10 ((systemat ${ }^{\star}$ or opportunist* $^{\star}$ or target $^{\star}$ or population or mass) near/2 assess ${ }^{\star}$ )

\#11 MeSH descriptor Electrocardiography, this term only

\#12 MeSH descriptor Electrocardiography, Ambulatory, this term only

\#13 (electrocardiogram*)

$\# 14$ (electrocardiograph ${ }^{\star}$ )

$\# 15$ (ecg)

$\# 16$ (ekg)

\#17 (holter)

\#18 (event monitor ${ }^{\star}$ )

\#19 MeSH descriptor Pulse, this term only

\#20 (pulse near/3 test)

\#21 (pulse near/3 tests)

\#22 (\#1 OR \#2 OR \#3 OR \#4 OR \#5 OR \#6 OR \#7 OR \#8 OR \#9 OR \#10 OR \#11 OR \#12 OR \#13 OR \#14 OR \#15 OR \#16 OR \#17 OR \#18 OR \#19

OR \#20 OR\#21)

\#23 MeSH descriptor Atrial Fibrillation, this term only

\#24 atrial fibrillation*

\#25 (auricular fibrillation*)

\#26 (atrium fibrillation*)

\#27 (af)

\#28 (a-fib)

\#29 MeSH descriptor Atrial Flutter, this term only

\#30 atrial flutter*

\#31 (auricular flutter ${ }^{\star}$ )

\#32 (\#23 OR \#24 OR \#25 OR \#26 OR \#27 OR \#28 OR \#29 OR \#30 OR \#31)

\#33 (\#22 AND \#32)

\section{MEDLINE}

1 Mass Screening/ (72995)

2 screen*.tw. (363165)

3 Diagnosis/ (16201)

4 "Diagnostic Techniques and Procedures"/ (1840)

5 diagnos*.tw. (1357269)

6 identif*.tw. (1481939)

7 test $^{\star}$. tw. $(1765452)$

8 prevalence.tw. (294233)

9 incidence ${ }^{\star} . t w . ~(429563)$

10 ((systemat ${ }^{\star}$ or opportunist ${ }^{\star}$ or target ${ }^{\star}$ or population or mass) adj2 assess $\left.{ }^{\star}\right)$.tw. (6956)

11 Electrocardiography/ (154517)

12 Electrocardiography, Ambulatory/ (8229)

13 electrocardiogram*.tw. (29533)

14 electrocardiograph*.tw. (33936)

15 ecg.tw. (40730)

16 ekg.tw. (2117)

17 holter.tw. (7374)

18 event monitor*.tw. (603)

19 or/1-18 (4696543) 
20 Atrial Fibrillation/ (28648)

21 atrial fibrillation*.tw. (29152)

22 auricular fibrillation*.tw. (740)

23 atrium fibrillation ${ }^{\star}$.tw. (7)

24 af.tw. (15627)

25 a-fib.tw. (29)

26 Atrial Flutter/ (4663)

27 atrial flutter ${ }^{\star}$.tw. (3879)

28 auricular flutter ${ }^{\star}$. tw. (213)

29 or/20-28 (46988)

30 Pulse/ (15989)

31 (pulse adj3 test).tw. (633)

32 (pulse adj3 tests).tw. (94)

3319 or 30 or 31 or 32 (4707679)

3429 and 33 (22662)

35 randomized controlled trial.pt. (321630)

36 controlled clinical trial.pt. (83679)

37 randomized.ab. (226659)

38 placebo.ab. (129223)

39 clinical trials as topic.sh. (158452)

40 randomly.ab. (163835)

41 trial.ti. (97314)

4235 or 36 or 37 or 38 or 39 or 40 or 41 (746444)

43 exp animals/ not humans.sh. (3683920)

4442 not 43 (688202)

4534 and $44(2438)$

\section{EMBASE}

1 mass screening/ (45098)

2 screen ${ }^{\star}$.tw. (481715)

3 diagnostic procedure/ (68098)

4 diagnosis/ (991556)

5 diagnos*.tw. (1978130)

6 ((systemat* ${ }^{\star}$ or opportunist* or target $^{\star}$ or population or mass) adj2 (assess ${ }^{\star}$ or test $\left.\left.^{\star}\right)\right)$. .tw. (17875)

7 identif*.tw. (1871499)

8 test ${ }^{\star}$. tw. $(2435524)$

9 prevalence.tw. (385646)

10 incidence ${ }^{\star}$.tw. (621772)

11 electrocardiography/ (126772)

12 electrocardiogram*.tw. (41746)

13 electrocardiograph*.tw. (47763)

14 ecg.tw. (70264)

15 ekg.tw. (3746)

16 holter.tw. (10268)

17 event monitor ${ }^{\star} . t w$. (849)

18 (pulse adj3 test ${ }^{\star}$ ).tw. (1412)

191 or 2 or 3 or 4 or 5 or 6 or 7 or 8 or 9 or 10 or 11 or 12 or 13 or 14 or 15 or 16 or 17 or 18 (6827758)

20 heart atrium fibrillation/ (60141)

21 atrial fibrillation.tw. (44810)

22 auricular fibrillation*.tw. (1890)

23 atrium fibrillation.tw. (31)

24 af.tw. (26527)

25 a-fib.tw. (88)

26 atrial flutter ${ }^{\star}$.tw. (5705)

27 auricular flutter ${ }^{\star} . t w$. (493)

28 or/20-27 (81706)

29 random\$.tw. (711679)

30 factorial\$.tw. (18953)

31 crossover\$.tw. (42881)

32 cross over\$.tw. (19756)

33 cross-over\$.tw. (19756) 
34 placebo\$.tw. (176052)

35 (doubl\$ adj blind\$).tw. (132159)

36 (singl\$ adj blind\$).tw. (11978)

37 assign\$.tw. (199920)

38 allocat\$.tw. (67235)

39 volunteer\$.tw. (161161)

40 crossover procedure/ (32434)

41 double blind procedure/ (108197)

42 randomized controlled trial/ (301358)

43 single blind procedure/ (14951)

4429 or 30 or 31 or 32 or 33 or 34 or 35 or 36 or 37 or 38 or 39 or 40 or 41 or 42 or 43 (1197077)

45 (animal/ or nonhuman/) not human/ (4367025)

4644 not 45 (1055312)

4719 and 28 and 46 (3896)

\section{WHAT'S NEW}

\begin{tabular}{lll}
\hline Date & Event & Description \\
\hline 24 August 2021 & Review declared as stable & $\begin{array}{l}\text { The research question as it is framed in this review is no longer } \\
\text { an active area. }\end{array}$ \\
\hline
\end{tabular}

\section{H I S T O R Y}

Protocol first published: Issue 1, 2012

Review first published: Issue 4, 2013

\begin{tabular}{lll}
\hline Date & Event & Description \\
\hline 8 January 2016 & $\begin{array}{l}\text { New citation required but conclusions } \\
\text { have not changed }\end{array}$ & No new studies for inclusion identified. Conclusions not changed \\
\hline 11 November 2015 & New search has been performed & Search updated to November 2015 \\
\hline
\end{tabular}

\section{CONTRIBUTIONS OF AUTHORS}

All review authors contributed to the production of this systematic review. PM wrote the protocol with input from all other review authors. PM developed the search strategy, with input from the Cochrane Heart Group Trials Search Co-ordinator (TSC). PM and CT performed study selection, assessed risk of bias and extracted and analysed the data. SS and MR provided clinical and methodological guidance and advised on interpretation of the results. PM wrote the review, with contributions from all review authors to the final revision.

\section{DECLARATIONS OF INTEREST}

No conflicts of interest are reported.

\section{SOURCES OF SUPPORT}

\section{Internal sources}

- No sources of support provided

\section{External sources}

- Health Research Board, Ireland

The lead author was awarded a Cochrane Fellowship 2010 by the Health Research Board (HRB) for the purpose of completing this review. 


\section{DIFFERENCES BETWEEN PROTOCOL AND REVIEW}

The protocol included the Database of Abstracts of Reviews of Effects (DARE) and the Institute of Scientific Information (ISI) Web of Science, along with conference proceedings from the list of databases to be searched. Given the high volume of results returned from MEDLINE, EMBASE and the Cochrane Central Register of Controlled Trials (CENTRAL), we did not include these two databases in the search.

The original review included the Cumulative Index to Nursing and Allied Health Literature (CINAHL) and the websites of Eurostroke (European Stroke Conference), the European Heart Rhythm Association (EHRA) and the American College of Cardiology (ACC) among the resources searched. We did not include these in the updated search because of the high level of overlap between CINAHL and EMBASE/ MEDLINE/CENTRAL and the low probability of studies reported only on the websites of professional organisations, particularly given that inclusion criteria were limited to randomised controlled trials (RCTs) in the updated search (see below).

The original protocol included quasi-experimental studies in the list of eligible studies. In the updated review, inclusion criteria were narrowed to include RCTs only. The original search failed to identify any quasi-experimental studies but did find one completed RCT and two RCTs that are currently in progress. Given the lower risk of bias associated with RCTs, the additional benefit of including quasiexperimental studies that may be carried out in the future is limited; therefore, the review focused exclusively on RCTs.

\section{N DEX TERMS}

\section{Medical Subject Headings (MeSH)}

Asymptomatic Diseases; Atrial Fibrillation [ ${ }^{\star}$ diagnosis]; ${ }^{\star}$ Electrocardiography; Mass Screening [ ${ }^{\star}$ methods]; Palpation [ ${ }^{\star}$ methods]; Pulse [methods]; Randomized Controlled Trials as Topic

\section{MeSH check words}

Aged; Female; Humans; Male 